WSRC-TR-98-00158

\title{
Thermal Analysis of Repository Codisposal Waste Packages Containing Aluminum Spent Nuclear Fuel
}

by

S. Y. Lee

Westinghouse Savannah River Company

Savannah River Site

Aiken, South Carolina 29808

R. L. Sindelar

This paper was prepared in connection with work done under the above contract number with the U.S. Department of Energy. By acceptance of this paper, the publisher and/or recipient acknowledges the U. S. Government's right to retain a nonexclusive, royalty-free license in and to any copyright covering this paper, along with the right to reproduce and to authorize others to reproduce all or part of the copyrighted paper. 
WSRC-TR-98-00158

Thermal Analysis of Repository Codisposal Waste Packages Containing Aluminum Spent Nuclear Fuel (U)

Si Young Lee

Robert L. Sindelar

Westinghouse Savannah River Company Savannah River Site Aiken, SC 29808

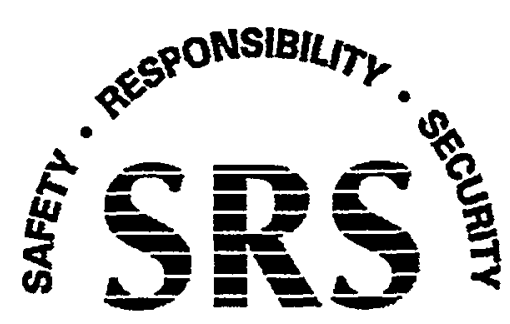




\section{DISCLAIMER}

This report was prepared as an account of work sponsored by an agency of the United States Government. Neither the United States Government nor any agency thereof, nor any of their employees, makes any warranty, express or implied, or assumes any legal liability or responsibility for the accuracy, completeness, or usefulness of any information, apparatus, product, or process disclosed, or represents that its use would not infringe privately owned rights. Reference herein to any specific commercial product, process, or service by trade name, trademark, manufacturer, or otherwise does not necessarily constitute or imply its endorsement, recommendation, or favoring by the United States Government or any agency thereof. The views and opinions of authors expressed herein do not necessarily state or reflect those of the United States Government or any agency thereof.

This report has been reproduced directly from the best available copy.

Available to DOE and DOE contractors from the Office of Scientific and Technical Information, P.O. Box 62, Oak Ridge, TN 37831; prices available from (615) 576-8401.

Available to the public from the National Technical Information Service, U.S. Department of Commerce; 5285 Port Royal Road, Springfield, VA 22161. 


\section{DISCLAIMER}

Portions of this document may be illegible in electronic image products. Images are produced from the best available original document. 


\section{WSRC-TR-98-00158}

KEYWORDS:

Thermal Analysis

Spent Nuclear Fuel

Co-Disposal Waste Package

Direct Disposal

Melt-Dilute Co-Disposal

RETENTION - Permanent

\section{Thermal Analysis of Repository Codisposal Waste Packages Containing Aluminum Spent Nuclear Fuel (U)}

SAVANNAH RIVER TECHNOLOGY CENTER

Si Young Lee

Robert L. Sindelar

Publication Date: April, 1998

Westinghouse Savannah River Company

Savannah River Site

Aiken, SC 29808

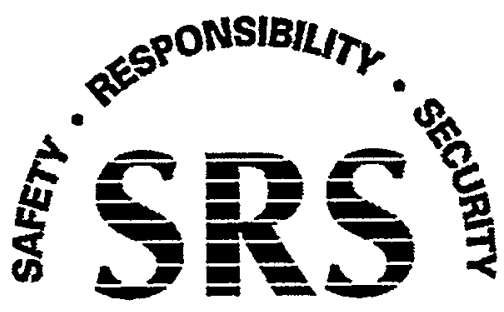

SAVANNAH RIVER SITE

Prepared for the U.S. Department of Energy under Contract No. DE-AC09-96SR18500 
(This Page Intentionally Left Blank) 
DOCUMENT: WSRC-TR-98-00158

TITLE: $\quad$ Thermal Analysis of Repository Codisposal Waste Packages Containing Aluminum Spent Nuclear Fuel (U)

TASK: $\quad$ SRT-MTS-97-2030

APPROVALS
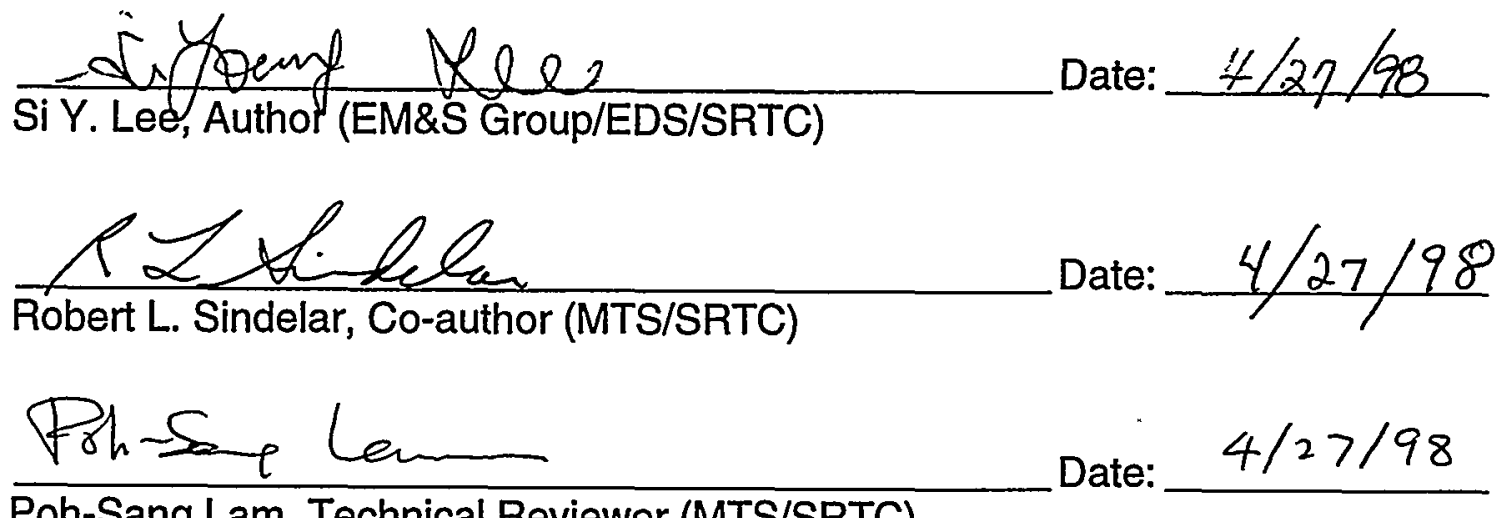

Poh-Sang Lam, Technical Reviewer (MTS/SRTC)
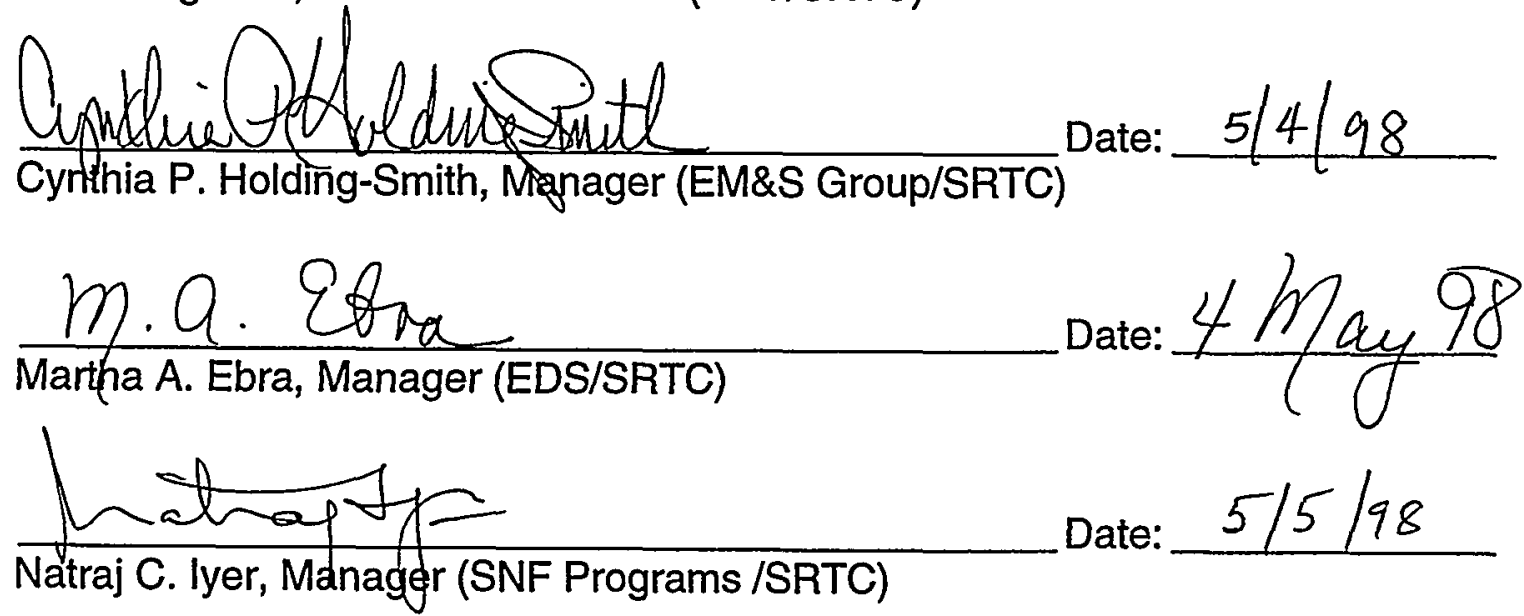

Date: $5 / 5 / 98$

Tami L. Capeletti, Manager (MTS /SRTC)

Date: $5 / 6 / 98$

$\omega 7$ twits

Date: $\delta / 7 / 98$

William F. Swift, Customer (SFS Engineering)

- ii- 
(This Page Intentionally Left Blank) 


\section{Table of Contents}

$\begin{array}{ll}\text { Abstract } & 1\end{array}$

1 Introduction 1

2 Acceptance Criteria $\quad 3$

3 Analysis Approach for Codisposal Waste Canister 5

3.1 General Governing Equations and Solution Method .............................................. 5

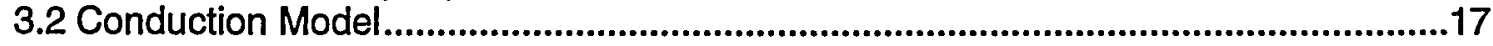

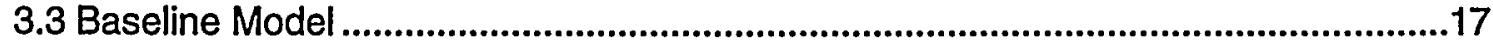

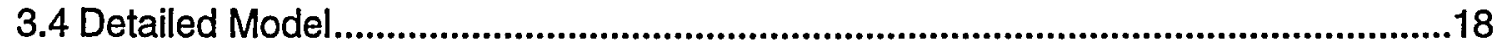

4 Modeling Assumptions and Design Parameters 18

5 Results and Discussions $\quad 25$

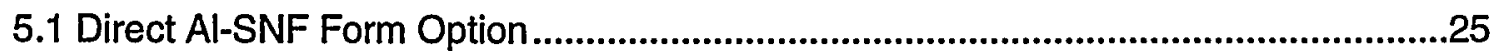

5.2 Melt-Dilute Al-SNF Form Option ..................................................................44

6 Conclusions $\quad 51$

7 Recommendations $\quad 52$

8 References 
(This Page Intentionally Left Blank) 


\section{List of Figures}

Figure 1. Horizontal emplacement of codisposal waste package in the center of drift repository. .....................................................................................................................4

Figure 2. Simplified diagram for thermal analysis approach methodology of codisposal waste package ..................................................................................................................6

Figure 3. Decay heat sources for direct codisposal SNF and HWGL regions as a function of storage time. The heat sources are provided in Ref. 1................................7

Figure 4. Decay heat sources for melt-dilute SNF and HWGL regions as a function of storage time. The heat sources are provided in Ref. 1 ..................................................8

Figure 5. Typical temperature and buoyancy-driven velocity profiles due to physical energy transport mechanism in an enclosed WP geometry............................................10

Figure 6. Thermal Modeling of codisposal SNF waste package in a geological repository..13

Figure 7. Non-uniform mesh grids of computational domain on the $x-y$ plane for the present model ..................................................................................................................14

Figure 8. Adequacy of the grid fineness for the present analysis (energy residual was computed by Eq. (6))...............................................................................................15

Figure 9. Maximum temperature of helium-cooled direct codisposal WP with bounding SNF decay heat source for baseline and conduction models as a function of storage time.

Figure 10. He-cooled direct codisposal WP temperature distribution for various storage times based on baseline model with bounding SNF decay heat source.

Figure 11. Temperature contour plot based on the baseline model for helium-cooled direct codisposal WP with bounding decay heat source at 0 years of storage time.....33

Figure 12. Comparison of centerline temperature distributions based on the baseline model and the detailed model for helium-cooled direct codisposal WP with bounding decay heat source.

Figure 13. Comparison of temperature distributions based on the baseline model and the detailed model for helium-cooled direct codisposal WP with bounding decay heat source.

Figure 14. Velocity vector plot of back-filled gas based on the detailed model for heliumcooled direct codisposal WP with bounding decay heat source at 0 years of storage time.

Figure 15. Temperature contour plot over the entire computational domain based on the detailed model for helium-cooled direct codisposal WP with bounding decay heat source at 0 years of storage time.

Figure 16. Back-filled gas flow pattern due to natural convective cooling within codisposal waste package.

Figure 17. Maximum temperature of air-cooled direct codisposal WP for the baseline and the conduction models with bounding SNF decay heat source and ambient temperature of $100^{\circ} \mathrm{C}$ as a function of storage time.

Figure 18. Comparison of maximum temperatures of air-cooled direct codisposal waste packages with bounding and nominal decay heat sources as a function of storage time based on the baseline model.

Figure 19. Temperature distribution of air-cooled direct codisposal waste package with nominal decay heat source as a function of storage time based on the baseline model. 
Figure 20. Maximum temperature of helium-cooled direct codisposal WP with bounding SNF decay heat source for the baseline and the conduction models with ambient temperatures of 100 and $150^{\circ} \mathrm{C}$ as a function of storage time.

Figure 21. Maximum temperatures of air-cooled and helium-cooled direct codisposal waste packages with bounding SNF decay heat loads for various geological ambient temperatures.

Figure 22. He-cooled $75 \%$ volume melt-dilute codisposal WP temperature distribution for various storage times based on the baseline model.

Figure 23. Temperature contour plot for He-cooled $75 \%$ volume melt-dilute codisposal WP based on the baseline model at 0 years of storage time.

Figure 24. Radial temperature distribution of He-cooled $90 \%$ volume melt-dilute codisposal WP for various storage times based on the baseline model.

Figure 25. Temperature contour plot for helium-cooled $90 \%$ volume melt-dilute codisposal WP based on the baseline model at 0 years of storage time. 49

Figure 26. Comparison of maximum temperatures for He-cooled $75 \%$ and $90 \%$ volume melt-dilute codisposal WP's for various storage times based on the baseline model. . 50

\section{List of Tables}

Table 1. Reference design conditions for the present thermal analysis.

Table 2. Upper bounding decay heat source in SNF canister and HWGL regions for direct codisposal WP.

Table 3. Nominal decay heat source in SNF canister and HWGL regions for direct codisposal WP.

Table 4. Bounding decay heat source in SNF canister and HWGL regions for codisposal WP filled to $75 \%$ of SNF volume with melt-dilute ingot.

Table 5. Bounding decay heat source in SNF canister and HWGL regions for codisposal WP filled to $90 \%$ of SNF volume with melt-dilute ingot.

Table 6. Thermal/radiation properties of the direct codisposal canister components used for the present analysis.

Table 7. Comparison of maximum temperatures for helium-cooled and air-cooled direct codisposal waste packages with bounding heat source based on the baseline model for various storage times (ambient temperature $=100^{\circ} \mathrm{C}$ )

Table 8. Comparison of maximum temperatures for air-filled direct codisposal waste package with bounding and nominal decay heat loads based on the baseline model for various storage times (ambient temperature $=100^{\circ} \mathrm{C}$ ).

Table 9. Peak temperatures of the direct codisposal waste package with bounding decay heat loads using the baseline model under 100 and $150^{\circ} \mathrm{C}$ ambient temperatures for various cooling times.

Table 10. Comparison of maximum temperatures for helium-filled direct codisposal waste package with bounding decay heat loads using the baseline model under 100 and $150^{\circ} \mathrm{C}$ ambient temperatures for various storage times.

Table 11. Thermal/radiation properties of the melt-dilute codisposal canister components used for the present analysis (Ref. 6).

Table 12. Comparison of peak temperatures for the melt-dilute codisposal WP with bounding decay heat loads based on the baseline model for various storage times (ambient temperature $=100^{\circ} \mathrm{C}$ ) 


\section{Abstract}

The engineering viability of disposal of aluminum-clad, aluminum-based spent nuclear fuel (Al-SNF) in a geologic repository requires a thermal analysis to provide the temperature history of the waste form. Calculated temperatures are used to demonstrate compliance with criteria for waste acceptance into the Mined Geologic Disposal System and as input to assess the chemical and physical behavior of the waste form within the waste package.

A thermal analysis methodology was developed to calculate peak temperatures and temperature profiles of Al-SNF in the DOE spent nuclear fuel canister within a codisposal waste package. A two-dimensional baseline model with conduction and radiation coupled heat transport was developed to evaluate the thermal performance for both the direct and the melt-dilute Al-SNF forms in a codisposal waste package canister over the range of possible heat loads and boundary conditions. In addition, a conduction model and a detailed model which includes convection were developed to identify the dominant cooling mechanism under the present waste package configuration, to investigate physical cooling mechanism in detail, and to estimate the conservatism imbedded in the baseline model.

The results of the baseline model showed that both the direct disposal and the meltdilute disposition configurations with a helium-filled waste package (WP) satisfied the present acceptance criteria for the WP design in terms of the peak temperature criterion, $\mathrm{T}_{-} \leq 350^{\circ} \mathrm{C}$, under the reference boundary conditions. A period of 10 years' cooling time for the decay heat loads of the SNF and the High-level Waste Glass Log (HWGL) regions was used as one of the reference design conditions. The melt-dilute form has evolved since these analyses were completed. A parametric analysis is currently underway to evaluate the various melt-dilute form options.

Many of the reference conditions are not confirmed. For example, waste package and DOE canister materials and dimensions and the thermal history of the repository will change as the final designs are developed. When the key information affecting the thermal performance of the waste forms is confirmed, the baseline model will be used to analyze the final design configuration.

\section{Introduction}

A thermal analysis is made to calculate peak temperatures and profiles of the codisposal waste package (WP). The leading codisposal WP design proposes that a central DOE spent nuclear fuel (SNF) canister be surrounded by five defense waste process facility (DWPF) glass log canisters, that is, High-level Waste Glass Logs (HWGL's), and placed into a WP in the Mined Geologic Disposal System (MGDS). The waste package is cylindrical with a diameter of about $6 \mathrm{ft}$. A DOE SNF canister having about 17 inch diameter and about $10 \mathrm{ft}$ length is placed along the central horizontal axis of the waste package. The five HWGL's, each with a $2 \mathrm{ft}$ diameter and $10 \mathrm{ft}$ length, will be located around the peripheral region of the DOE SNF canister within the WP container. The codisposal WP will be laid down horizontally in a drift repository as shown in Fig. 1. 
There are two waste form options for Al-SNF disposition using the codisposal WP design configuration. They are the

- direct Al-SNF form and the

- melt-dilute AI-SNF form.

For the direct form option, a total of up to 64 standard-sized Material Test Reactor (MTR) type Al-SNF fuel assemblies, some with highly-enriched U, are to be packed in a DOE SNF canister. For the melt-dilute form option, a number of AI-SNF assemblies are melted and diluted to be emplaced in the central DOE SNF stainless steel canister, which result in a SNF canister containing uranium-aluminum alloy ingots. For the present analysis, a SNF canister is estimated to be filled to $75 \%$ or to $90 \%$ of the canister volume with an uranium-aluminum alloy ingot. The composition of an ingot will have the eutectic composition of the binary alloy (13.2 wt. \% uranium, $86.8 \mathrm{wt}$. \% aluminum) with less than and equal to $20 \%$ enriched uranium- 235 .

The transient decay heat loads were recently developed for this analysis (Ref. 1). The heat loads included: i) the Al-SNF assemblies in the direct form; ii) the melt-dilute form for the case where all the krypton and $80 \%$ of the cesium assumed to be removed; and iii) the HWGL. The Al-SNF heat loads were using the ORIGEN code under SCALE 4.2 system (Ref. 1). The heat source for the various melt-dilute form options has evolved since these analyses were completed. The heat source term will be updated and additional cases will be run.

Thermal performance analysis of the codisposal WP for licensing would be performed for the specific design conditions and thermal history of a geological repository. This information is not available at this time. Therefore, reference design conditions were assumed to perform the analyses. The assumed reference conditions are shown in Section 4 (see Table 1). In addition, sensitivity analyses for key design parameters of the codisposal WP were performed over a range of boundary conditions.

The objective of this study is to develop a thermal analysis methodology and to perform analyses of codisposal storage configurations to estimate the SNF, HWGL, and WP temperatures in a geological repository for various boundary conditions. This report addresses thermal performance internal to the codisposal WP (see Fig. 1 for the present model boundary) since thermal analysis modeling of hydro-geological media including the geological drift tunnel region is beyond the scope of the present work. Three thermal models were developed to assess the thermal performance of the codisposal WP design using intact prototypic geometry created under the body-fitted coordinate system in the computational fluid dynamics (CFD) preprocessing environment. The first model considers conduction only. The second model is the baseline model including the conduction and radiation cooling mechanisms under various combinations of decay heat source terms and codisposal WP design parameters. The present baseline analysis uses the baseline model based on a parametric approach to evaluate thermal performance for each WP design option since the baseline model is the most efficient one among them in terms of computational time and reasonable accuracy. The third model is the detailed model considering the convection and radiation as well as conduction cooling processes to estimate the conservatism of the baseline model for a typical design condition and to understand the physical cooling mechanism in full detail for the present codisposal WP design. The CFX code has been used as a tool to model and simulate the thermal performance for 
the direct and melt-dilute codisposal WP's in a drift geological tunnel repository. It had been previously used to simulate and benchmark the test data for the interim dry spent nuclear fuel storage canister with reasonable accuracy. The three-dimensional modeling methodology and benchmarking results for the interim SNF storage canister are documented in Reference 2.

The modeling and simulation results will show that the present baseline model can predict reasonably accurate thermal performance for direct and melt-dilute Al-SNF options in the codisposal WP. It is expected that this approach can be used to accurately predict thermal performance of similar fuels in various WP configurations.

The thermal analysis results will be used to demonstrate compliance with the waste acceptance criteria for the MGDS and as input to assess the chemical and physical behavior of the Al-SNF forms within the WP.

\section{Acceptance Criteria}

Criteria for acceptance of SNF and high-level waste forms into the federal repository or MGDS are being compiled by the U. S. Department of Energy, Office of Civilian Radioactive Waste Management (OCRWM) as part of the preparation for submission of the system for licensing by the Nuclear Regulatory Commission. The development of the repository acceptance criteria is understood to be an ongoing process. The present draft criteria are contained in Reference 3, the MGDS Draft Disposability Interface Specification. In this recent draft, the criteria are referred to as "disposability standards."

The approach in the Alternative Technology Program is to show conformance with the disposability standards (Ref. 4). Two standards from Reference 3 can be addressed using the results from the heat source development work (Ref. 1) and thermal analysis work in this report. The demonstration of conformance would need to be updated as both the disposability standards and the design of the MGDS waste package and DOE SNF canister evolve.

Disposability Standard 2.4.20 - Limits on Total Thermal Output for Disposable Canisters specifies that "no disposable single-element SNF canister shall have a thermal output in excess of 1500 watts at the time of shipment to the MGDS. Multi-element canister thermal outputs are addressed in Disposability Standard 2.4.21." Tables 2 through 5 in this report show that the highest total thermal output of the various loading configurations of Al SNF forms in the DOE canister is 681 watts, well-within the 1500 watt standard. The time of zero years in the tables corresponds to a time of ten years cool down following reactor operation with the assembly.

Disposability Standard 2.4.21 - Limits on Disposable Multi-Element Canister Thermal Design specifies that "SNF cladding for assemblies placed in disposable canisters shall not exceed $350^{\circ} \mathrm{C}$. This shall be shown through calculation to be achievable over 1000 years. This calculation shall include the following inputs and assumptions.

- Decay heat assumed in the calculation shall be calculated using decay-heat generation curves appropriate for the specific SNF in the canister.

- Temperatures at the canister surface should be assumed to be as follows, with "Year Zero" defined as the time the canister leaves the waste-custodian site. 


$\begin{array}{lr}\text { Year } & \text { Temperature } \\ 0-1 & 150^{\circ} \mathrm{C} \\ 1-5 & 175^{\circ} \mathrm{C} \\ 5-50 & 190^{\circ} \mathrm{C} \\ >50 & 200^{\circ} \mathrm{C}\end{array}$

The detailed thermal modeling and analysis in this report for the assumed reference conditions show that the temperature criterion is met. Figures 10 and 24 are the waste package temperature profile results for using the upper bound heat sources for the direct and melt-dilute forms, respectively, with a helium gas backfill in both the DOE SNF and the WP. The AI SNF form maximum temperature is below $350^{\circ} \mathrm{C}$ even with the canister temperature above $200^{\circ} \mathrm{C}$ at time zero. It should be noted that the present calculations provide information that shows that temperatures are below the temperature limit. As previously stated, this information will support the performance assessment of the Al SNF forms under repository conditions including interactions with packaging materials.

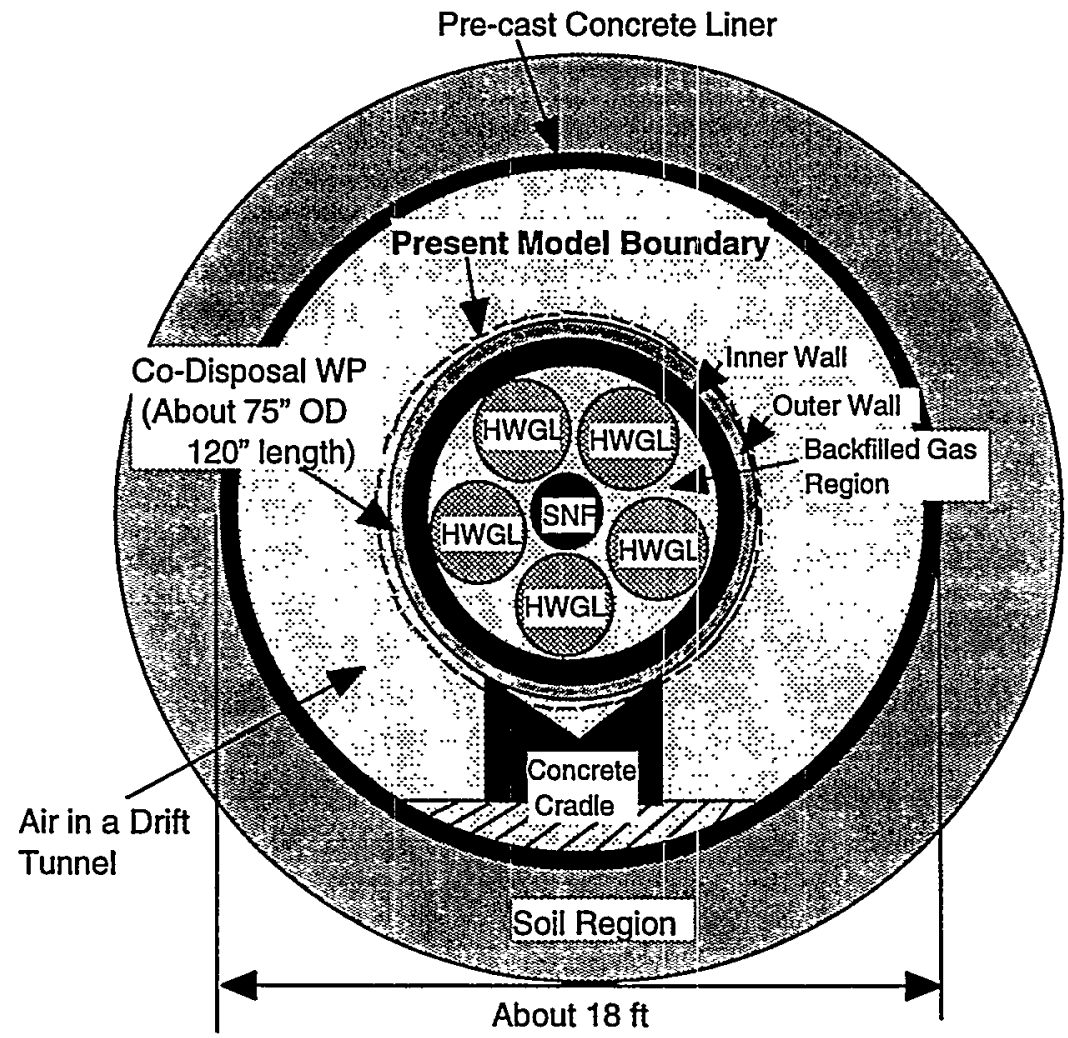

Figure 1. Horizontal emplacement of codisposal waste package in the center of drift repository. 


\section{Analysis Approach for Codisposal Waste Canister}

Thermal performance analysis for the codisposal WP design for each Al-SNF form option, namely, the direct and the melt-dilute forms, is performed as a function of storage time for various boundary conditions by using a parametric analysis approach. The initial storage time, "Year 0 ", is defined as the time the canister leaves the site and is put into the WP canister and emplaced in the repository. For the present analysis, initial times for the SNF and the HWGL are assumed to be 10 years cooling time after fuel discharge from the reactor and after the production of high-level waste glass log. The WP temperatures are then computed for selected times during the first 2000 years after emplacement in the repository. A quasi-steady state temperature distribution is assumed for each selected time since the package transient temperatures will reach equilibrium in a few days. The present modeling boundary is shown in Fig. 1. For a typical reference design condition such as helium-cooled, intact codisposal WP, the physical cooling mechanism is also investigated to understand how decay heat energy is transported through the WP to the geological environment. Specifically, how the waste package temperature affects the buoyancy-driven natural circulation inside the WP, and what is the most dominant mode of thermal energy transport for the present codisposal WP configuration are investigated. This information may be important to assess corrosion degradation of the WP and to determine the movement of moisture outside the WP boundary. The approach methodology for the present thermal analysis is shown in Fig. 2.

\subsection{General Governing Equations and Solution Method}

The codisposal WP contains five HWGL's and one central SNF canister. The codisposal canister is horizontal at the center of a geological drift tunnel as schematically shown in Fig. 1. The HWGL and SNF regions have different decay heat sources, and the SNF canister is surrounded by five HWGL canisters. The WP will be filled with air or helium, possibly in combination with other filler material such as neutron poisons, depending on the design. Solid regions of the SNF and HWGL canisters have time-dependent heat sources. The present thermal analysis uses well-defined heat source terms for the SNF and HWGL regions (Ref. 1). Thermal and material properties for structural materials of the WP and the melt-dilute ingot are also defined (Refs. 5 and 6). A typical transient decay heat curve for the DOE canister with the direct SNF form is shown in Fig. 3. Figure 4 shows the non-dimensional decay heat for the DOE canister containing melt-dilute SNF ingot.

The heat generated by the nuclear decay will be cooled by back-filled gas medium and eventually will be transported to the geological medium through the physical mechanisms of conduction, convection, and radiation heat transport processes. In this situation the decay heat energy of the SNF and HWGL regions is transported from one point in a solid medium to another only through conduction mechanism, and heat transfer at the solid wall boundary is computed using thermal conductivity of the gas and fluid temperature gradient at the wall boundary. The fluid temperature gradient at the wall is dependent on the gas flow field driven by the density gradient at the wall boundary layer since the temperature gradient is dependent on the rate at which the gas fluid convects the heat away. Thus energy transport is coupled to the momentum transport through the wall interface of the solid and fluid regions. 


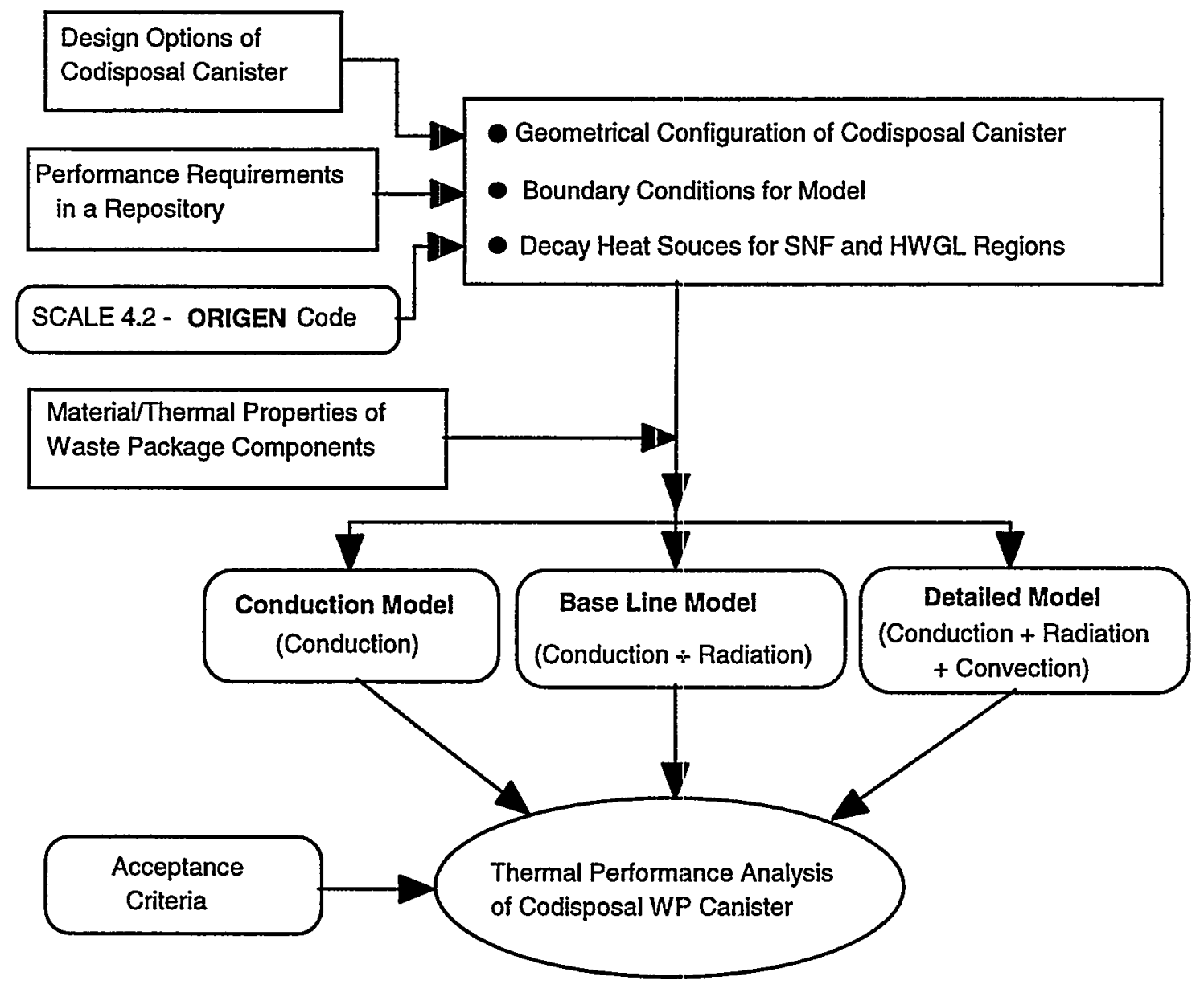

Figure 2. Simplified diagram for thermal analysis approach methodology of codisposal waste package 


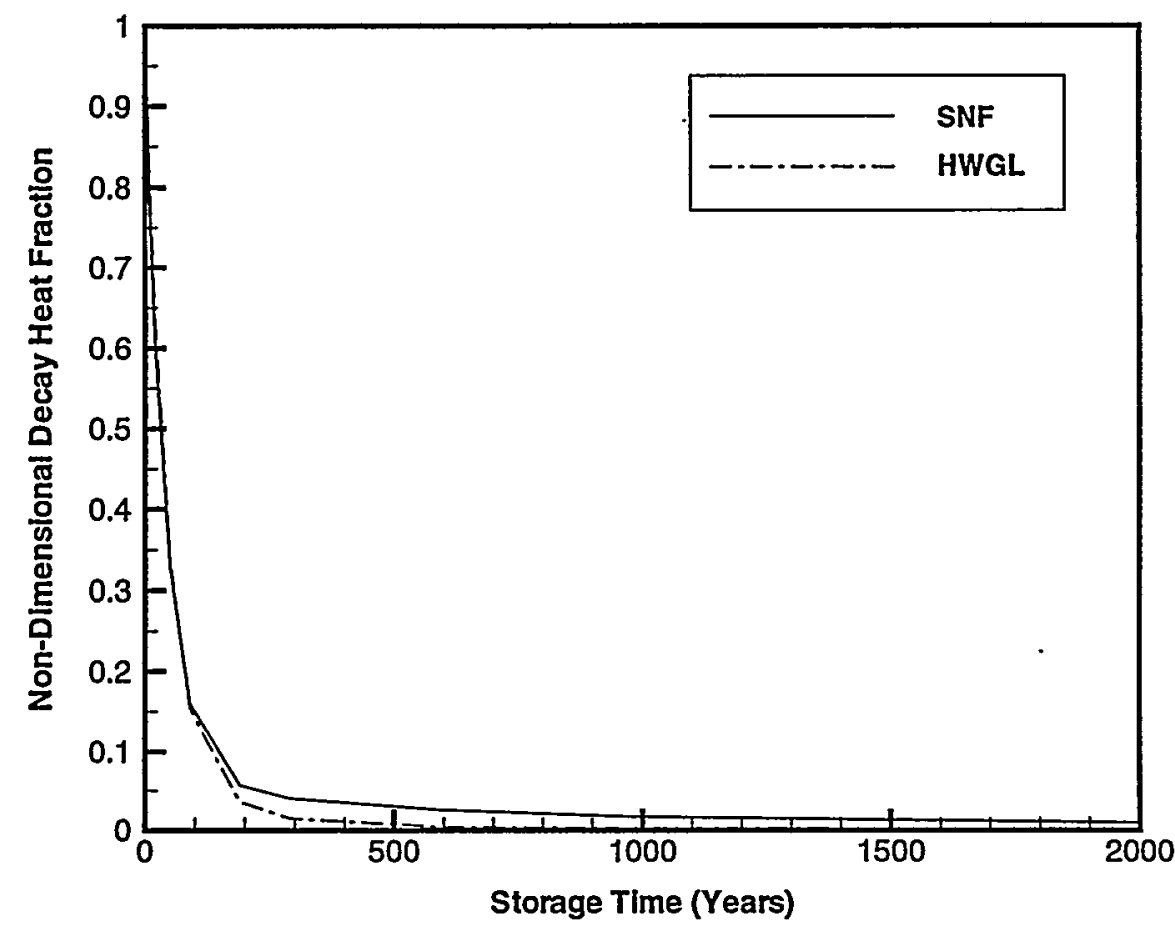

Figure 3. Decay heat sources for direct codisposal SNF and HWGL regions as a function of storage time. The heat sources are provided in Ref. 1. 


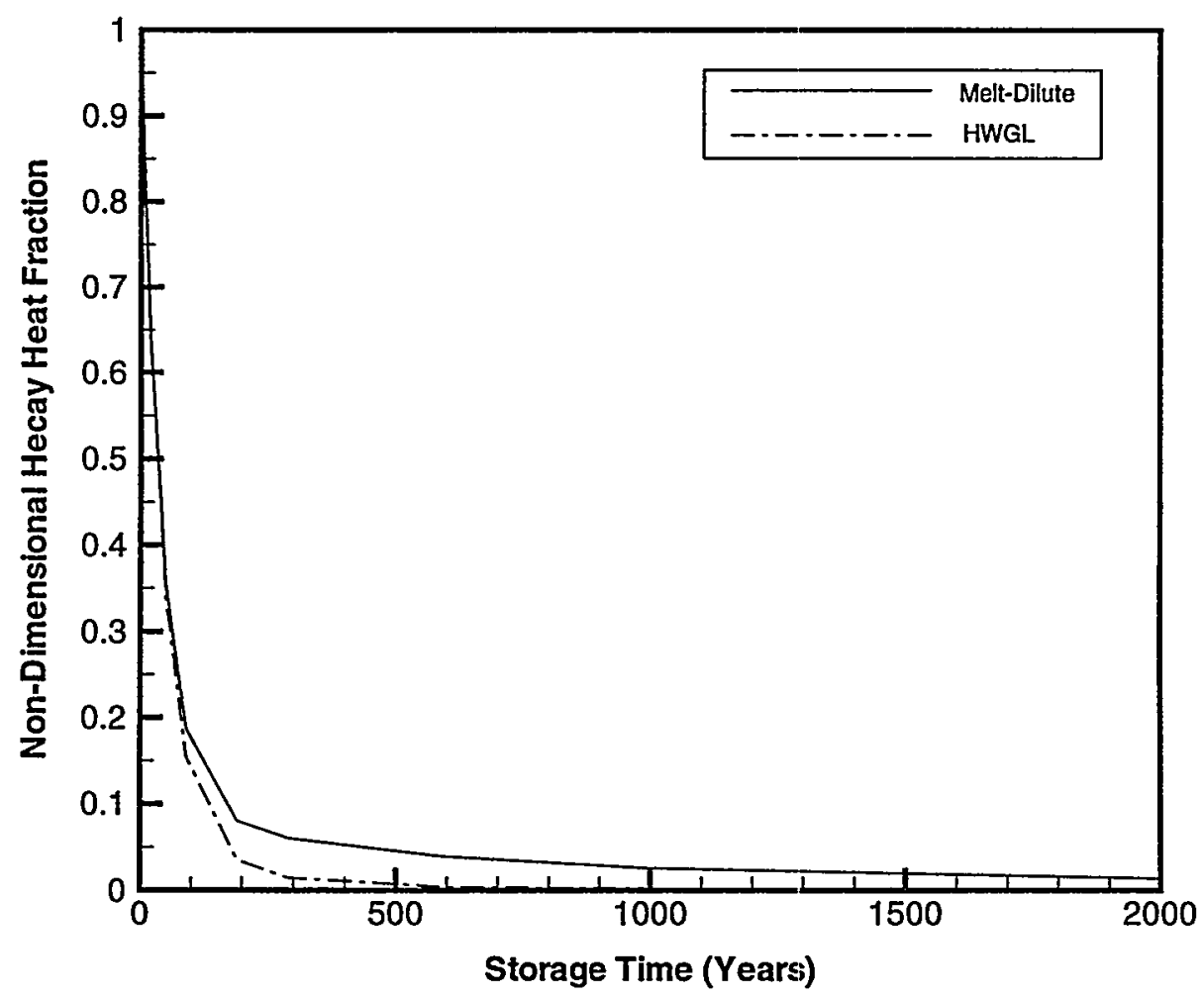

Figure 4. Decay heat sources for melt-dilute SNF and HWGL regions as a function of storage time. The heat sources are provided in Ref. 1 . 
In contrast to the mechanisms of the conduction and convection, where energy transport through a material medium is involved, heat may also be transferred by the propagation of electromagnetic wave through the gas or vacuum in case of high temperature environment. This electromagnetic radiation is emitted at the surface of a solid body which has been thermally excited; and when it strikes another body, part may be reflected, part may be transmitted, and part may be absorbed. If the incident radiation is thermal radiation with the proper wavelength, the absorbed radiation will appear as heat within the absorbing body. Heat due to the radiation mechanism may pass from one body to another without the need of a medium of transport between them. Like the present situation, there may be a separating medium, such as helium or air, which is unaffected by this passage of energy. There will be a continuous interchange of energy between two radiating bodies, with a net exchange of energy from the hotter to the colder. The basic governing equations of thermal energy transport must be coupled with those of fluid motion and electromagnetic radiation of body surface in order to describe, mathematically, the process of energy transfer. Therefore, the detailed model considers heat transfer mechanisms driven by convection and radiation as well as conduction within an enclosed codisposal WP.

Typical flow and temperature profiles under actual process of energy transport mechanism including a buoyancy-driven natural convection caused by the fluid temperature gradient are illustrated in Fig. 5. Temperature decreases rapidly due to the convective and radiative cooling effects within a boundary layer region, as shown in the illustration. The boundary layer flow is a buoyancy-induced motion resulting from body forces acting on density gradients which, in turn, arise from temperature gradients in the fluid. It is virtually impossible to observe pure heat conduction in a gas medium because as soon as a temperature difference is imposed on a fluid, natural convection currents will occur as a result of density differences. The gravitational body force is oriented in the negative $y$-direction for the present analysis.

The governing equations for the present two-dimensional analysis under the Cartesian coordinate system are shown below.

For the mass continuity,

$$
\frac{\partial \rho}{\partial t}+\frac{\partial(\rho u)}{\partial x}+\frac{\partial(p v)}{\partial y}=0
$$

where $\rho$ is the density of the medium and $u$ and $v$ are the local velocities in the $x$ and $y$ directions, respectively. 


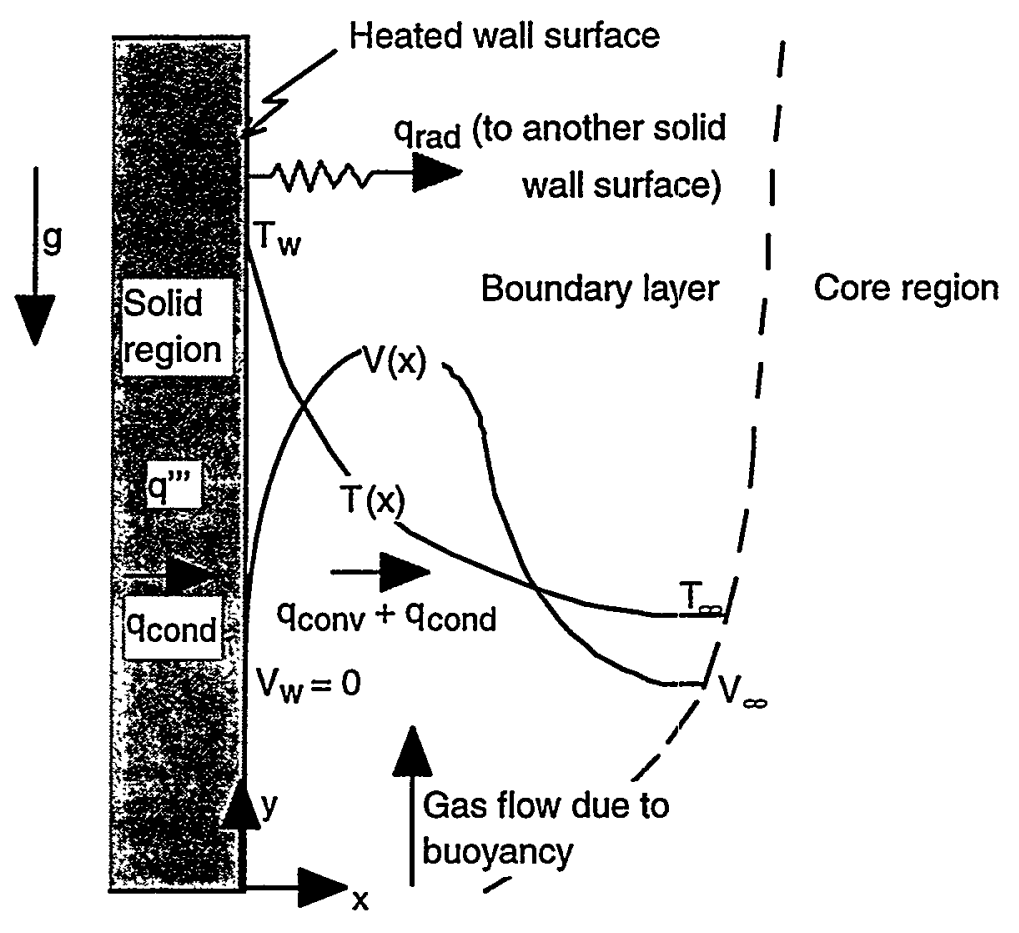

Figure 5. Typical temperature and buoyancy-driven velocity profiles due to physical energy transport mechanism in an enclosed WP geometry.

For the momentum equation in tensor notation,

$$
\rho\left(\frac{\partial u_{i}}{\partial t}+u_{j} \frac{\partial u_{i}}{\partial x_{j}}\right)=\frac{\partial \sigma_{i j}}{\partial x_{j}}+X_{i}
$$

where the variables with the subscript, $i$ (or $j)=1$, or 2 , correspond to those of the $x-$, or $y$-direction, respectively. $\sigma_{i j}$ is the stress tensor and $X_{i}$ the body force term.

$$
\begin{aligned}
& \sigma_{\mathrm{ij}}=-\mathrm{P} \delta_{\mathrm{ij}}+\mu\left(\frac{\partial \mathrm{u}_{\mathrm{i}}}{\partial \mathrm{x}_{\mathrm{j}}}+\frac{\partial \mathrm{u}_{\mathrm{j}}}{\partial \mathrm{x}_{\mathrm{i}}}\right) \\
& \delta_{\mathrm{ij}}=\left(\begin{array}{l}
1 \text { for } \mathrm{i}=\mathrm{j} \\
0 \text { for } \mathrm{i} \neq \mathrm{j}
\end{array}\right) \\
& \mathrm{X}_{1}=0 \text { for the present model and } \mathrm{P}=\text { fluid pressure. }
\end{aligned}
$$

For a general energy balance equation on a control volume of the waste package,

$$
\rho \frac{\mathrm{Dh}}{\mathrm{Dt}}-\frac{\partial}{\partial \mathrm{x}}\left\{\mathrm{k} \frac{\partial \mathrm{T}}{\partial \mathrm{x}}\right\}-\frac{\partial}{\partial \mathrm{y}}\left\{\mathrm{k} \frac{\partial \mathrm{T}}{\partial \mathrm{y}}\right\}+\frac{\partial}{\partial \mathrm{x}}\left\{\mathrm{q}_{\mathrm{rx}}\right\}+\frac{\partial}{\partial \mathrm{y}}\left\{\mathrm{q}_{\mathrm{ry}}\right\}-\beta \mathrm{T} \frac{\mathrm{DP}}{\mathrm{Dt}}-\Phi-\mathrm{q}^{\prime \prime}=0
$$


where $\Phi$ is viscous dissipation term, $h$ thermodynamic enthalpy, $q_{r x}, q_{r y}$ radiative heat fluxes in the $x$ - and $y$-directions, and $q^{\prime \prime \prime}$ heat generation source term. The viscous dissipation term is not included in the present model.

From eq. (3), energy terms within a control volume of a fluid medium in the waste package includes convection $(\vec{v} \cdot \nabla T)$, conduction $(k \nabla T)$, radiation heat transfer $\left(q_{r}\right)$, internal heat sources (q"'), compression work of back-filled gas ( $\beta T(D P / D t))$, and energy storage due to transients $\left(\rho d \mathrm{~h} / \partial \mathrm{t}=\rho \mathrm{C}_{\mathrm{p}} \delta^{\prime} \mathrm{l} / \partial \mathrm{t}\right)$. Storage of radiant energy within the control volume is generally negligible; hence no modification of the usual transient terms will be considered as a result of the radiation field. Radiation pressure is negligible relative to the fluid pressure and hence does not contribute to the compression work term. As shown in eq. (3), the net inflow of radiant energy per unit volume can be written as the negative of the divergence of a radiant heat flux vector $\vec{q}_{r}$. Assuming that probability of emission of a given photon wavelength $(\lambda)$ for any surface in an enclosure obeys Kirchoff's law, $\varepsilon(\lambda)=\alpha(\lambda)$, radiative heat flux in eq. (3) becomes

$\mathrm{q}_{\mathrm{si}}=\alpha \sigma \mathrm{T}^{4}=\varepsilon \sigma \mathrm{T}^{4}$

where $\mathrm{i}=\mathrm{x}$ or $\mathrm{y}$.

In eq. (4) $\alpha$ and $\varepsilon$ are absorption and emission coefficients of wall surface, and $\sigma$ is Stefan-Boltzman's constant $\left(5.670 \times 10^{-8} \mathrm{~W} / \mathrm{m}^{2} \mathrm{~K}^{4}\right)$. Under the present SNF storage conditions, the energy storage due to transients, viscous dissipation, and gas compression work terms are negligible relative to the main heat transfer mechanisms such as conduction, convection, and radiation.

For the detailed modeling analysis, the Boussinesq approximation was used for the gravitational term in the momentum equation to include the buoyancy-induced natural convection. It is a two-part approximation: It neglects all variable property effects in the governing equations and it approximates the density difference term with a simplified equation of state, that is, the gravity term in the $y$-direction, $X_{2}=-\rho g$, in eq. (2) is replaced by the following relation:

$$
\rho g=\rho_{\infty}\left\{1-\beta\left(T-T_{\infty}\right)\right\} g
$$

where $\beta$ is thermal expansion coefficient, and $\rho_{\infty}$ is the density at $T=T_{\infty}$.

Natural convective flow regimes for the helium-cooled and the air-cooled WP designs may be estimated based on the non-dimensional quantity, Grashof number $\left(\mathrm{Gr}_{\mathrm{L}}\right)$, which is the parameter describing the ratio of buoyancy to viscous forces. The Grashof number performs much the same function for natural convection flow as the Reynolds $(\mathrm{Re})$ number does for forced convection. Under normal conditions one may expect that the laminar-to-turbulent transition will take place at about $\mathrm{Gr}_{\mathrm{L}} \approx 10^{9}$.

For a typical helium-cooled WP design,

$$
\mathrm{Gr}_{\mathrm{L}}=\frac{\mathrm{g} \beta \mathrm{L}^{3}\left(\mathrm{~T}_{\mathrm{w}}-\mathrm{T}_{\infty}\right)}{v^{2}}
$$




$$
\approx 1.40 \times 10^{7}<1.0 \times 10^{9} \text { (laminar flow) }
$$

where $L=$ characteristic length parameter $(=1.7545 \mathrm{~m})$,

$$
\begin{aligned}
& \beta=\text { thermal expansion coefficient }\left(=2.00 \times 10^{-3} \mathrm{~K}^{-1}\right), \\
& T_{W}=\text { wall temperature, } \\
& T_{\infty}=\text { ambient temperature, } \\
& v=\text { kinematic viscosity }\left(=2.91 \times 10^{-4} \mathrm{~m}^{2} / \mathrm{sec}\right)
\end{aligned}
$$

For air-cooled WP design, Grashof number $\left(\mathrm{Gr}_{L}\right)$ is

$$
\begin{aligned}
& \mathrm{Gr}_{\mathrm{L}} \approx 7.35 \times 10^{8} \\
& \text { where } \beta=2.00 \times 10^{-3} \mathrm{~K}^{-1}, \\
& \qquad v=3.80 \times 10^{-5} \mathrm{~m}^{2} / \mathrm{sec} .
\end{aligned}
$$

Page:

12 of 54

This corresponds to the near-transition flow according to the literature information (Ref. 9). For the present analysis, natural convection regime within the waste package is assumed to be laminar.

These governing equations are applied to the two-dimensional computation domain depending on the physical model for the thermal performance analysis of the codisposal WP. A 1/2 sector model of the codisposal WP was used as a computational domain for a better computational efficiency by imposing symmetrical boundary conditions on the diagonal centerline of the WP cross-sectional plane. Fig. 6 presents the present $1 / 2$ sector model.

The two-dimensional geometry file was created using the multi-block preprocessor of the CFX code under the body-fitted coordinate system, which allows the treatment of non-orthogonal geometry. Initially, an attempt was made to build a non-uniform fine meshing with progressive change of grid size near the conduction-convection interface as well as radiation to capture detailed temperature and velocity boundary layer behavior. However, the model was not run in an efficient way on SGI R10000 workstation platform because of large computational requirements for more than 100000 grid cells.

For the present analysis, an optimum grid of 9822 cells was established from the grid sensitivity analysis under SGI workstation environment. The WP canister model consists of 195 element blocks and 7 different material zones on the $x-y$ computational plane. Two-dimensional meshes are presented in Fig. 7. Adequacy of grid fineness for the present computational domain is illustrated in Fig. 8. 


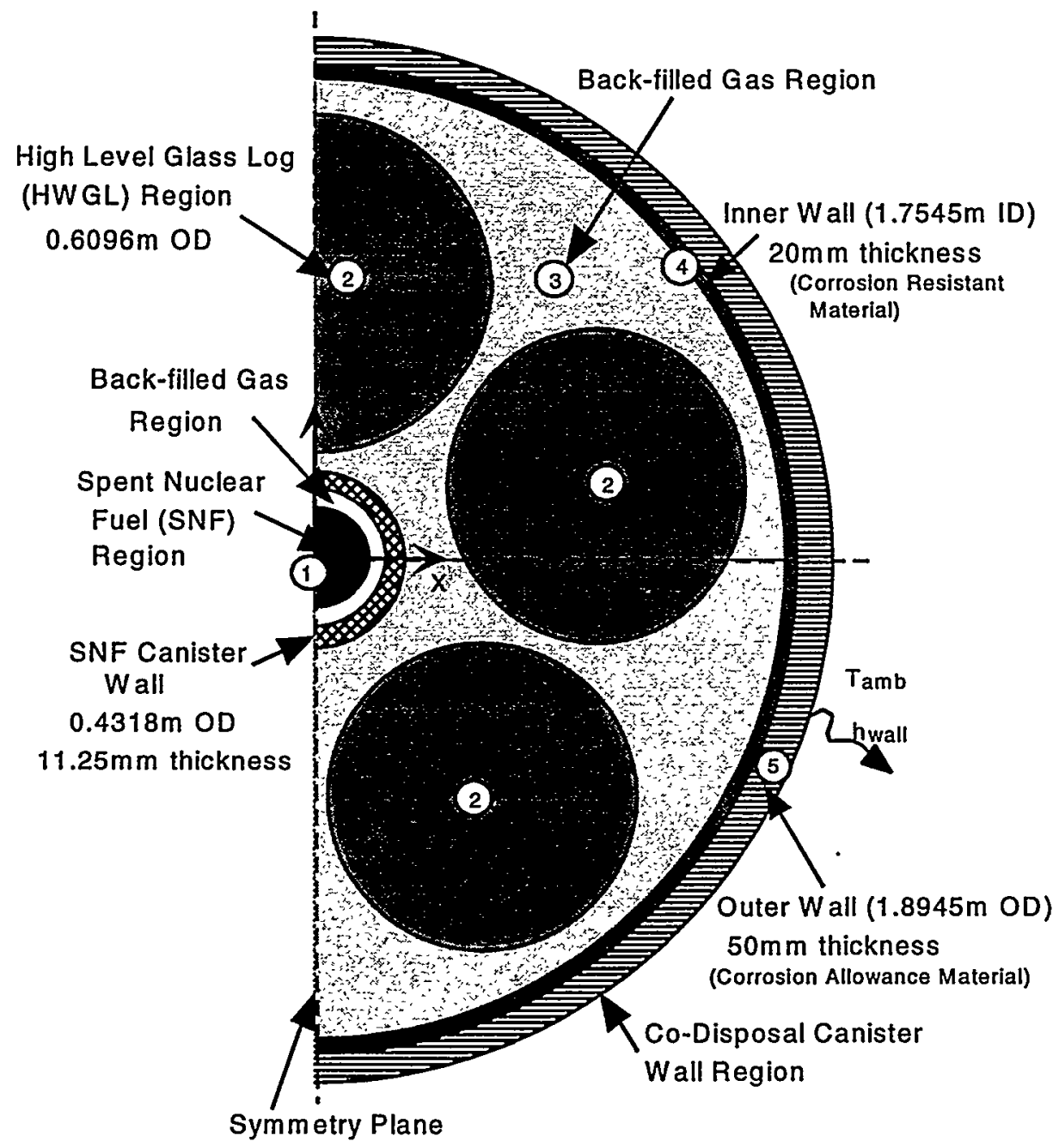

Figure 6. Thermal Modeling of codisposal SNF waste package in a geological repository.

The baseline model assumed negligible convective contribution from natural convection compared to conduction and thermal radiative heat transfer mechanisms since the elevation difference between the lowest and the highest temperatures is not large for the present geometrical configuration. However, the detailed model considered convection along with conduction and radiation.

The segregated solution technique was selected for the efficient run of the conductionconvection coupled problem with an internal heat source. The linearized equations in each control volume were derived by integrating transport equations for mass, momentum, and energy at the center of each cell volume on the computational domain. 


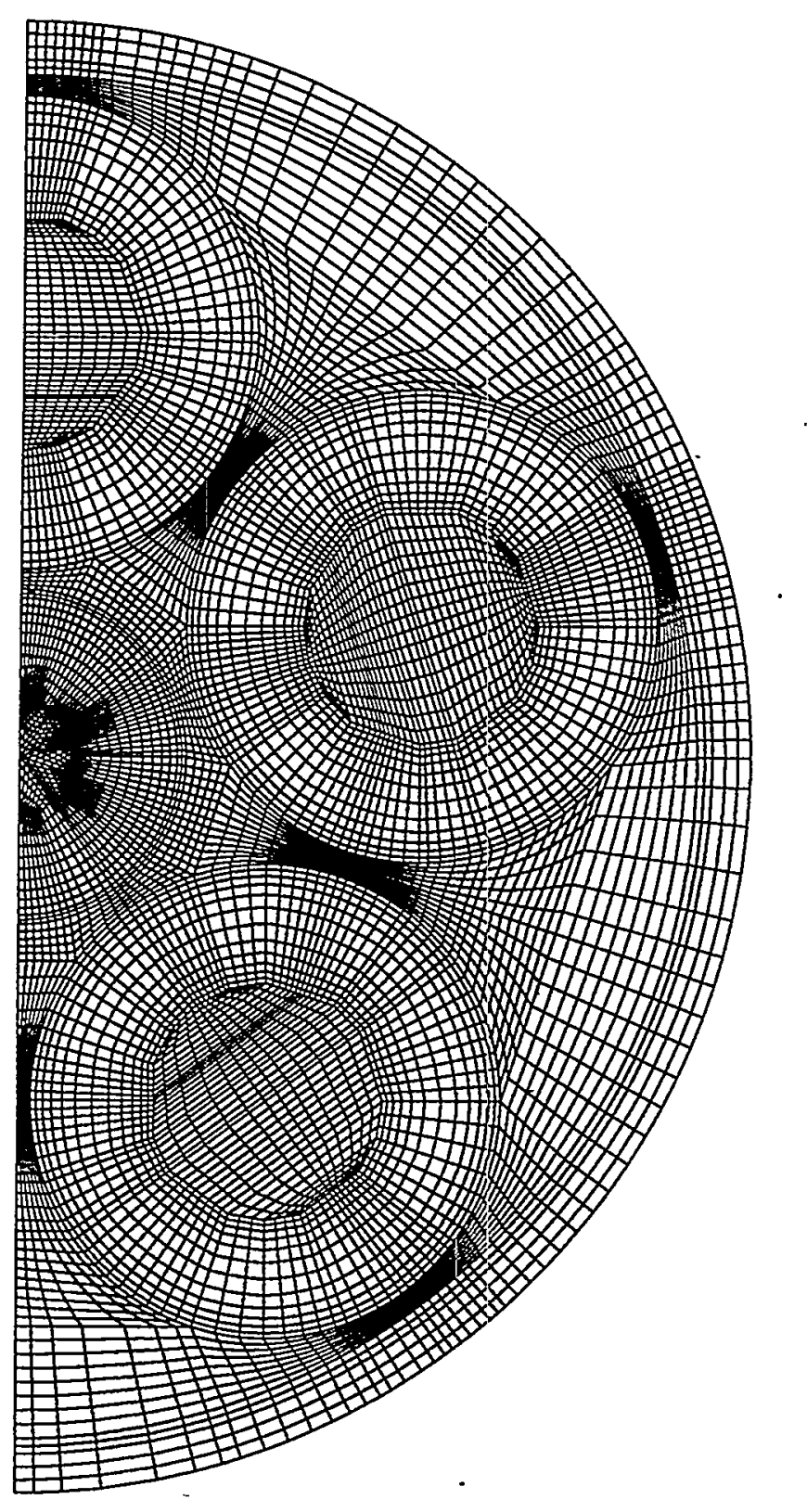

Figure 7. Non-uniform mesh grids of computational domain on the $x-y$ plane for the present model 


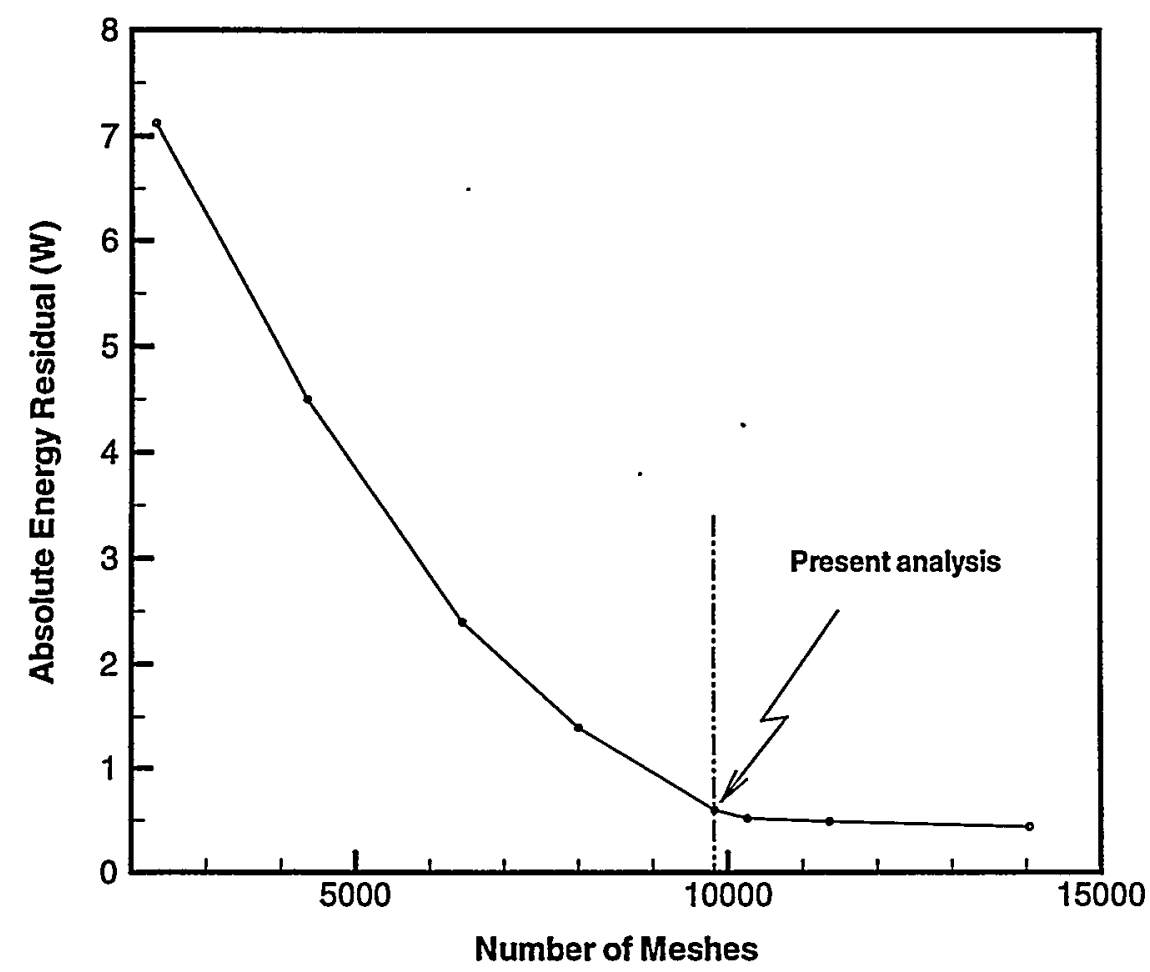

Figure 8. Adequacy of the grid fineness for the present analysis (energy residual was computed by Eq. (6)).

The hybrid scheme of the Peclet number weighted central-forward differencing was used to obtain the finite difference approximations of continuity, momentum, and energy conservation equations for the fluid region.

All variables such as $u, v, P$, and $T$ for the present two-dimensional detailed model are computed at the center of each node cell. CFX code used the non-staggered grid approach to obtain the velocity components on control volume faces from those on control volume centers by using the Rhie-Chow interpolation method since the staggered grid approach prohibitively requires large storage of geometric information to describe a fully non-orthogonal grid. The transient solution is desired, but this can be achieved by dropping the transient term completely from the equations and using a purely iterative approach since steady state temperature distribution of the codisposal WP is reached within a couple of days for each transient decay heat source term. For the present detailed model analysis, the quasi-steady approach was used by solving the transient equations with conduction, convection and radiation cooling effects. This approach was proven to be an efficient method in the benchmarking test of the code. For the conduction model and the baseline model analyses, natural convective cooling mechanism was neglected, and quasi-steady state approach was taken for a 
computational efficiency since the codisposal WP is emplaced horizontally in geological drift tunnel.

In the CFX code, the complete set of governing equations is not solved by a direct method since the direct method requires excessive computational effort. The CFX solution method ignores the non-linearity of the original differential equations. Thus, two levels of iteration are used: an inner iteration to solve for the spatial coupling for each variable and an outer iteration to solve for the coupling between variables. Heat transfer by radiation can be included in any CFX calculation. The separate radiation program (CFX-Radiation) is used to calculate the radiative heat fluxes because complex nonlocal procedure is required to calculate radiative heat transfer. For the present analysis, the radiation calculation was performed by using discrete transfer method solving a differential radiative energy equation rather than Monte Carlo method using statistical approach. Thus, CFX-Radiation uses the cell volume temperature obtained from the CFX solution in order to calculate the cell volume heating due to radiation, and the updated radiative heat fluxes are then passed back to the CFX solver in the form of volumetric heat sources. This updating process is repeated periodically within the given number of the outer iterations.

Each variable is taken in sequence with all other variables fixed so that a discretized transport equation for that variable is formed for every cell in the flow domain and the problem is handed over to a linear equation solver which returns the updated values of the variable. The non-linearity of the original equations is simulated by reforming the coefficients of the discrete equations, using the most recently computed values of the variables, before each inner iteration. However, the treatment of pressure is different from the foregoing description since it does not obey an original transport equation. Instead simplified versions of the discrete momentum equations are used to derive a functional relationship between a correction to the pressure and corrections to the velocity components in each cell. Substitution of this expression into the continuity equation leads to an equation linking the pressure correction with the continuity error in each cell. The solution is used both to update pressure and to correct the velocity field through the pressure-velocity functional relationship in order to check the mass conservation. This numerical algorithm is known as the Semi-Implicit Method for Pressure-Linked Equations (SIMPLE) in the literature (Ref. 10). The residual continuity error $\left(\varepsilon_{m}\right)$ is obtained by substituting three pressure-corrected velocity components into the mass continuity equation for the cell control volume. The residual term of the mass continuity, $\varepsilon_{\mathrm{m}}$, serves as an indicator of the convergence of the flow field solution in the CFX code. The iterations are continued until the $\varepsilon_{\mathrm{m}}$ values for every cell are within a tolerance, which is provided by the user input. It is noted that $\varepsilon_{\mathrm{m}}$ is a dimensional quantity (default unit: $\mathrm{kg} / \mathrm{sec}$ ). For the present analysis, the value of $\varepsilon_{\mathrm{m}}$ was used as 1.0 $\times 10^{-6} \mathrm{~kg} / \mathrm{sec}$ for a convergence check. In addition, the overall energy balance should be checked to demonstrate the adequacy of the grid used. This was done by using equation (6).

$R=-\int_{A_{w}} q_{w}^{\prime \prime} d A+q^{\prime \prime \prime} V_{F}$

where $q_{W}^{\prime \prime}$ is heat flux along the WP wall surface boundary, and $A_{W}$ and $V_{F}$ are total wall surface area and fuel region volume, respectively.

Volumetric heat source term, $q^{\prime \prime \prime}$, in equation (6) is given by the user input. In all cases considered here, $R$ (energy residual) is less than about 0.7 watt as shown in Fig. 8. 


\subsection{Conduction Model}

The mathematical equation governing conductive cooling in the WP medium can be obtained from the energy balance equation (3) neglecting the contributions of convection and radiation terms. In this model, convective cooling due to buoyancydriven gas circulation and radiative cooling effect are neglected, which leads to extremely conservative estimation for thermal performance of the codisposal design. The primary objectives for performing the thermal analyses using a conduction model, a conduction and radiation model (baseline model); and a conduction, radiation, and convection model (detailed model) are:

(a) to find out what the upper bounding estimation is in terms of thermal performance of the present codisposal WP and

(b) to investigate what the most dominant cooling mechanism is for the WP design configuration among the three potential cooling modes, conduction, radiation, and convection, using the other two model results. A $1 / 2$ sector geometry model of the codisposal WP was used for a better computational efficiency by imposing symmetrical boundary conditions on the centerline of the package as shown in Fig. 6 .

\subsection{Baseline Model}

The baseline model neglects natural convective cooling mechanism driven by back-filled gas buoyancy due to temperature gradient in a back-filled gas medium of the codisposal WP. The model assumes that thermal energy transported by conduction and radiation plays key role in the assessment of thermal performance for the codisposal WP. Thus, only the energy balance on a control volume of the WP shown in eq. (3) is considered for the baseline modeling analysis. Mass and momentum transports in eqs. (1) and (2) become zero assuming that gas medium within the WP is frozen.

For steady state with no heat source in a transparent and frozen gas medium, energy balance given by eq. (3) becomes

(Heat Conducted into Surface $I, q_{\text {cond, },}$ )

$$
=\left(\text { Radiant Heat lost from Surface } I, q_{\mathrm{rad}, \mathrm{l}}\right)
$$

When convection term is not included for the baseline model, the heat conducted into a wall surface is balanced by the radiant heat lost from the wall surface as shown in eq. (7). For the present baseline analysis, a two-dimensional, steady state, conductionradiation model was developed using uniformly-distributed heat generation sources within HWGL region and SNF canister to predict the codisposal package thermal performance in a geological repository. Buoyancy-induced natural convection term will be considered later for the detailed model to simulate thermal performance of the waste package and to quantify the conservatism of the conduction-radiation model. The model used a 1/2 sector geometry model of the codisposal WP for a better computational efficiency by imposing symmetrical boundary conditions on the centerline of the package as shown in Fig. 6. The baseline model will be used for the sensitivity runs with respect to the reference conditions. The reference conditions are shown in Table 1. Finally, the analysis results will be provided to the degradation model of the waste package for the structural integrity analysis. 


\subsection{Detailed Model}

The detailed model considers heat transfer mechanisms driven by convection and radiation as well as conduction for an enclosed codisposal waste package (WP). This model was applied to the direct codisposal WP for the reference design condition. The primary purpose of this model is to estimate the conservatism of the baseline model for a typical design condition and to understand the physical cooling mechanism for the present codisposal WP design. Non-uniform package surface temperature due to the internal natural convection of the WP container may affect the movement of moisture source outside the WP boundary, which is closely related to structural material corrosion, since the baseline model can not capture this phenomena although there is slight difference between the two models in terms of maximum temperature predictions. The model used a $1 / 2$ sector geometry model of the codisposal WP for a better computational efficiency.

\section{$4 \quad$ Modeling Assumptions and Design Parameters}

The present analyses are made for the thermal performance of the codisposal WP containing direct aluminum-clad DOE spent fuel assemblies or melt-dilute ingot based on the alternative SNF disposal technology. The computational modeling domain is shown in Fig. 6. Figure 7 presents two-dimensional computational meshes used for the present analysis. A quasi-steady state temperature distribution was assumed for a selected time since the waste package transient temperatures will reach equilibrium in a few days. The package was assumed to be laid down horizontally at the center of the geological repository drift tunnel as shown in Fig. 1. The geological ambient temperature around the package wall circumference was assumed to be uniform.

A typical natural convective heat transfer coefficient $(h)$ of $1.5 \mathrm{~W} / \mathrm{m}^{2}{ }^{\circ} \mathrm{C}$ was used 'as an external wall boundary condition for the present analysis. The present value of the heat transfer coefficient can be justified on the following basis:

For horizontally-oriented geometrical configuration, heat transfer coefficient (h) for natural convective cooling under laminar flow regime $\left(\mathrm{Gr}_{\mathrm{L}} \mathrm{Pr}<10^{\circ}\right)$ is given in terms of non-dimensional numbers empirically.

$$
\mathrm{Nu}_{\mathrm{L}}=\frac{\mathrm{hD}}{\mathrm{k}}=\mathrm{C}\left(\mathrm{Gr}_{\mathrm{L}} \mathrm{Pr}\right)^{\mathrm{m}} \quad \text { for } \mathrm{Gr}_{\mathrm{L}} \operatorname{Pr}>10^{4}
$$

where $C$ and $m$ are the coefficients determined by the literature data. $D$ is outer diameter of the WP, and $\operatorname{Pr}$ is the Prandtl number defined by $\left(\mu \mathrm{C}_{\mathrm{p}} / \mathrm{k}\right)$.

For long horizontal cylinder, $\mathrm{C}=0.525$ and $\mathrm{m}=0.25$ are given by Chapman (1974) using the experimental data (Ref. 7). From eq. (8), heat transfer coefficient $(h)$ is about 1.5 $\mathrm{W} / \mathrm{m}^{2}{ }^{\circ} \mathrm{C}$ corresponding to $\mathrm{Nu}_{\mathrm{L}} \approx 97$ conservatively under the present conditions. Theoretical approach was also taken to compute conservative natural convective heat transfer rate by using boundary layer theory in the previous work (Ref. 8)

Natural convection due to internal gas movement inside the waste package is neglected in the baseline model, but it is considered in the detailed model to investigate internal cooling mechanism of the codisposal WP containing aluminum-clad DOE SNF in detail since the baseline model can not capture the physical cooling mechanism due to natural circulation within the WP container. Effective thermal conductivity for the fuel 
assemblies of the SNF canister was used as volumetric-averaged value in terms of volume fraction of each different material constituent in the SNF canister (Ref. 2). Heat loads for the SNF and HWGL regions were provided to the model (see Eq. (3)) as volumetric source densities by assuming that heat generation for each region is uniformly distributed. The bounding and nominal volumetric heat sources for direct codisposal WP are presented in Table 2 and Table 3 . The bounding volumetric sources for melt-dilute ingots filled with $75 \%$ and $90 \%$ of the SNF canister volume are shown in Table 4 and Table 5.

The main design parameters involved in the thermal performance of the waste package are:

- Different combinations of back-filled gases in the SNF canister and the waste package container (e.g., air-air, helium-helium)

- Various sets of combinations of two heat sources (bounding or nominal SNF and HWGL decay heat sources)

- Initial reference storage time related to the spent fuel cooling time before the emplacement of aluminum-clad DOE SNF assemblies into the WP container

- Internal structure materials of codisposal canister

- Repository temperature history since emplacement of WP

- Waste package location in a repository drift tunnel (center or corner of a drift tunnel): The present analysis was assumed that waste package is located at the center of a drift tunnel repository.

The thermal performance analysis for the codisposal WP requires known values for the design parameters listed above to study design options for a codisposal waste package. Some of them are not available at this time. For the present work, initial reference time was assumed to be 10 years' cooling time since the discharge from reactor and production of HWGL. It was also assumed to have no solid conduction paths among the SNF and HWGL canisters such that HWGL canisters, SNF canister, and codisposal canister inner wall do not touch each other since final geometrical configuration is neither confirmed nor available yet. Thus, reference conditions were used to perform the baseline analysis for each design option of the direct and melt-dilute codisposal waste package as shown in Table 1. Sensitivity analyses for some of the main design parameters were performed with respect to the reference conditions. 
Table 1. Reference design conditions for the present thermal analysis.

\begin{tabular}{|c|c|}
\hline 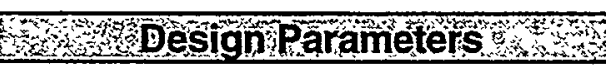 & - W Cosign Conditions \\
\hline $\begin{array}{l}\text { Back-filled gas inside / outside } \\
\text { of SNF canister in codisposal } \\
\text { WP }\end{array}$ & $\begin{array}{l}\text { - Helium gas inside and outside } \\
\text { of SNF canister }\end{array}$ \\
\hline $\begin{array}{l}\text { Transient decay heat loads for } \\
\text { SNF and HWGL }\end{array}$ & 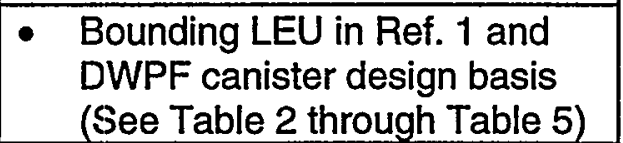 \\
\hline $\begin{array}{l}\text { - Initial reference time (storage } \\
\text { time: "Year } 0 \text { ") }\end{array}$ & $\begin{array}{l}\text { - } 10 \text { years cooling time since } \\
\text { discharge from reactor and } \\
\text { production of HWGL }\end{array}$ \\
\hline $\begin{array}{l}\text { - Internal structure of the WP } \\
\text { container }\end{array}$ & - Intact codisposal geometry \\
\hline $\begin{array}{l}\text { - Repository ambient } \\
\text { temperature }\end{array}$ & - $100^{\circ} \mathrm{C}$ \\
\hline $\begin{array}{l}\text { - WP location in a repository } \\
\text { tunnel }\end{array}$ & - $\mathrm{Ce}$ \\
\hline
\end{tabular}


Table 2. Upper bounding decay heat source in SNF canister and HWGL regions for direct codisposal WP.

\begin{tabular}{|c|c|c|c|c|c|}
\hline $\begin{array}{c}\text { Storage } \\
\text { Time } \\
\text { (yrs) }\end{array}$ & $\begin{array}{c}\text { Assembly } \\
\text { Power } \\
\text { (W/assembly) }\end{array}$ & $\begin{array}{c}\text { Power per } \\
\text { HWGL } \\
(W)\end{array}$ & $\begin{array}{c}\text { Total Power for } \\
\text { SNF Can. } \\
(W)\end{array}$ & $\begin{array}{c}\text { Volumetric SNF } \\
\text { Power } \\
(W / m 3)\end{array}$ & $\begin{array}{c}\text { Volumetric HWGL } \\
\text { Power } \\
\text { (W/m3) }\end{array}$ \\
\hline 0 & 8.58 & 472.3 & 549.12 & 2735.752 & 530.913 \\
\hline 10 & 6.53 & 375.99 & 417.92 & 2082.105 & 422.651 \\
\hline 20 & 5.243 & 301.35 & 335.552 & 1671.742 & 338.748 \\
\hline 50 & 2.83 & 159.5 & 181.12 & 902.352 & 179.294 \\
\hline 90 & 1.382 & 73.1 & 88.448 & 440.654 & 82.1718 \\
\hline 190 & 0.487 & 16.81 & 31.168 & 155.281 & 18.896 \\
\hline 290 & 0.3442 & 7.09 & 22.0288 & 109.749 & 7.9699 \\
\hline 590 & 0.2218 & 1.98 & 14.1952 & 70.721 & 2.2257 \\
\hline 990 & 0.1468 & 1.14 & 9.3952 & 46.808 & 1.2815 \\
\hline 1990 & 0.0794 & 0.72 & 5.0816 & 25.317 & 0.8094 \\
\hline 2990 & 0.063 & 0.62 & 4.032 & 20.088 & 0.6969 \\
\hline 5990 & 0.0505 & 0.52 & 3.232 & 16.102 & 0.5845 \\
\hline 9990 & 0.041 & 0.43 & 2.624 & 13.073 & 0.4834 \\
\hline 19990 & 0.0265 & 0.3 & 1.696 & 8.4496 & 0.3372 \\
\hline 49990 & 0.0103 & 0.16 & 0.6592 & 3.2842 & 0.1799 \\
\hline 99990 & 0.0034 & 0.11 & 0.2176 & 1.0841 & 0.1237 \\
\hline
\end{tabular}


Table 3. Nominal decay heat source in SNF canister and HWGL regions for direct codisposal WP.

\begin{tabular}{|c|c|c|c|c|c|}
\hline $\begin{array}{c}\text { Storage } \\
\text { Time } \\
\text { (yrs) }\end{array}$ & $\begin{array}{c}\text { Assembly } \\
\text { Power } \\
\text { (W/assembly) }\end{array}$ & $\begin{array}{c}\text { Power per } \\
\text { HWGL } \\
(W)\end{array}$ & $\begin{array}{c}\text { Total Power for } \\
\text { SNF Can. } \\
(W)\end{array}$ & $\begin{array}{c}\text { Volumetric SNF } \\
\text { Power } \\
\text { (W/m3) }\end{array}$ & $\begin{array}{c}\text { Volumetric } \\
\text { HWGL Power } \\
\text { (W/m3) }\end{array}$ \\
\hline 0 & 4.03 & 472.3 & 257.92 & 1284.974 & 530.913 \\
\hline 10 & 3.073 & 375.99 & 196.672 & 979.833 & 422.651 \\
\hline 20 & 2.453 & 301.35 & 156.992 & 782.145 & 338.748 \\
\hline 50 & 1.284 & 159.5 & 82.176 & 409.406 & 179.294 \\
\hline 90 & 0.594 & 73.1 & 38.016 & 189.398 & 82.172 \\
\hline 190 & 0.179 & 16.81 & 11.456 & 57.075 & 18.896 \\
\hline 290 & 0.1224 & 7.09 & 7.8336 & 39.028 & 7.9699 \\
\hline 590 & 0.0826 & 1.98 & 5.2864 & 26.337 & 2.2257 \\
\hline 990 & 0.0574 & 1.14 & 3.6736 & 18.302 & 1.2815 \\
\hline 1990 & 0.0345 & 0.72 & 2.208 & 11.000 & 0.8094 \\
\hline 2990 & 0.0285 & 0.62 & 1.824 & 9.0873 & 0.6970 \\
\hline 5990 & 0.0232 & 0.52 & 1.4848 & 7.3974 & 0.5845 \\
\hline 9990 & 0.0187 & 0.43 & 1.1968 & 5.9625 & 0.4834 \\
\hline 19990 & 0.012 & 0.3 & 0.768 & 3.8262 & 0.3372 \\
\hline 49990 & 0.0046 & 0.16 & 0.2944 & 1.4667 & 0.1799 \\
\hline 99990 & 0.0014 & 0.11 & 0.0896 & 0.4464 & 0.1237 \\
\hline
\end{tabular}


Table 4. Bounding decay heat source in SNF canister and HWGL regions for codisposal WP filled to $75 \%$ of SNF volume with melt-dilute ingot.

\begin{tabular}{|c|c|c|c|c|c|}
\hline $\begin{array}{c}\text { Storage } \\
\text { Time } \\
\text { (yrs) }\end{array}$ & $\begin{array}{c}\text { Assembly } \\
\text { Power } \\
\text { (W/assembly) }\end{array}$ & $\begin{array}{c}\text { Power per } \\
\text { HWGL } \\
(W)\end{array}$ & $\begin{array}{c}\text { Total Power for } \\
\text { SNF Can. } \\
(W)\end{array}$ & $\begin{array}{c}\text { Volumetric SNF } \\
\text { Power } \\
\text { W/m3) }\end{array}$ & $\begin{array}{c}\text { Volumetric } \\
\text { HWGL Power } \\
\text { (W/m3) }\end{array}$ \\
\hline 0 & 5.629 & 472.3 & 568.529 & 1890.181 & 530.913 \\
\hline 10 & 4.403 & 375.99 & 444.703 & 1478.498 & 422.651 \\
\hline 20 & 3.567 & 301.35 & 360.267 & 1197.775 & 338.748 \\
\hline 50 & 2 & 159.5 & 202 & 671.587 & 179.294 \\
\hline 90 & 1.0534 & 73.1 & 106.3934 & 353.725 & 82.172 \\
\hline 190 & 0.4539 & 16.81 & 45.8439 & 152.417 & 18.896 \\
\hline 290 & 0.3409 & 7.09 & 34.4309 & 114.472 & 7.9699 \\
\hline 590 & 0.2218 & 1.98 & 22.4018 & 74.479 & 2.2257 \\
\hline 990 & 0.1468 & 1.14 & 14.8268 & 49.295 & 1.2815 \\
\hline 1990 & 0.0794 & 0.72 & 8.0194 & 26.662 & 0.8094 \\
\hline 2990 & 0.063 & 0.62 & 6.363 & 21.155 & 0.6969 \\
\hline 5990 & 0.0505 & 0.52 & 5.1005 & 16.958 & 0.5845 \\
\hline 9990 & 0.041 & 0.43 & 4.141 & 13.768 & 0.4834 \\
\hline 19990 & 0.0265 & 0.3 & 2.6765 & 8.8985 & 0.3372 \\
\hline 49990 & 0.0103 & 0.16 & 1.0403 & 3.4587 & 0.1799 \\
\hline 99990 & 0.0034 & 0.11 & 0.3434 & 1.1417 & 0.1237 \\
\hline
\end{tabular}


Table 5. Bounding decay heat source in SNF canister and HWGL regions for codisposal WP filled to $90 \%$ of SNF volume with melt-dilute ingot.

\begin{tabular}{|c|c|c|c|c|c|}
\hline $\begin{array}{c}\text { Storage } \\
\text { Time } \\
(\mathrm{yrs})\end{array}$ & $\begin{array}{c}\text { Assembly } \\
\text { Power } \\
\text { (W/assembly) }\end{array}$ & $\begin{array}{c}\text { Power per } \\
\text { HWGL } \\
(W)\end{array}$ & $\begin{array}{c}\text { Total Power for } \\
\text { SNF Can. } \\
(\mathbf{W})\end{array}$ & $\begin{array}{c}\text { Volumetric SNF } \\
\text { Power } \\
(\mathrm{W} / \mathrm{m} 3)\end{array}$ & $\begin{array}{c}\text { Volumetric } \\
\text { HWGL Power } \\
(\mathrm{W} / \mathrm{m} 3)\end{array}$ \\
\hline 0 & 5.629 & 472.3 & 681.109 & 1887.062 & 530.913 \\
\hline 10 & 4.403 & 375.99 & 532.763 & 1476.058 & 422.651 \\
\hline 20 & 3.567 & 301.35 & 431.607 & 1195.798 & 338.748 \\
\hline 50 & 2 & 159.5 & 242 & 670.479 & 179.294 \\
\hline 90 & 1.0534 & 73.1 & 127.4614 & 353.141 & 82.172 \\
\hline 190 & 0.4539 & 16.81 & 54.9219 & 152.165 & 18.896 \\
\hline 290 & 0.3409 & 7.09 & 41.2489 & 114.283 & 7.9699 \\
\hline 590 & 0.2218 & 1.98 & 26.8378 & 74.356 & 2.2257 \\
\hline 990 & 0.1468 & 1.14 & 17.7628 & 49.213 & 1.2815 \\
\hline 1990 & 0.0794 & 0.72 & 9.6074 & 26.618 & 0.8094 \\
\hline 2990 & 0.063 & 0.62 & 7.623 & 21.120 & 0.6969 \\
\hline 5990 & 0.0505 & 0.52 & 6.1105 & 16.930 & 0.5845 \\
\hline 9990 & 0.041 & 0.43 & 4.961 & 13.745 & 0.4834 \\
\hline 19990 & 0.0265 & 0.3 & 3.2065 & 8.8838 & 0.3372 \\
\hline 49990 & 0.0103 & 0.16 & 1.2463 & 3.4530 & 0.1799 \\
\hline 99990 & 0.0034 & 0.11 & 0.4114 & 1.1398 & 0.1237 \\
\hline
\end{tabular}




\section{$5 \quad$ Results and Discussions}

Based on the approach methodology and the assumptions, the two-dimensional conduction model, conduction-radiation coupled model, and conduction-convectionradiation conjugated model were developed to investigate key parameters and to find sensitivities to the changes of the design parameters with respect to the reference conditions in relation to the thermal performance of intact codisposal waste package. CFD code such as CFX 4.1 was used as a tool to create geometry file under nonorthogonal mesh environment and body-fitted coordinate system and to solve the nonlinear conjugate equations by considering buoyancy-driven natural convective cooling mechanism and using discrete radiation transport technique. The present thermal performance analyses were made for the two options for aluminum-clad DOE SNF disposition using the codisposal WP design configuration. They are direct codisposal option and melt-dilute disposition option.

\subsection{Direct AI-SNF Form Option}

For the direct disposal option, codisposal WP consists of typical aluminum-clad DOE SNF assemblies such as MIT-type fuel and five HWGL canisters. Table 6 shows thermal and radiation properties of the codisposal package components containing direct disposal of SNF, which were used for the present analysis.

The two-dimensional thermal analyses were made based on the referenceable decay heat sources and material properties for the reference conditions shown in Table 1. The direct codisposal waste package temperatures were then computed for selected times during the first 2000 years after emplacement in the repository. Figure 9 shows maximum temperatures of the codisposal WP under the reference conditions as a function of storage time using the conduction model and the baseline model. The transient temperature distributions for the WP are based on local thermal loading of bounding SNF and HWGL heat sources given in Table 2. Maximum temperature for the baseline model is about $304^{\circ} \mathrm{C}$ at the initial storage time (0 year of storage time). The conduction model predicts maximum temperature by $121^{\circ} \mathrm{C}$ higher than the baseline model, that is, conduction-radiation coupled model, does. The detailed model considering all the three modes of thermal energy transport predicts about $303^{\circ} \mathrm{C}$ for the maximum temperature of the codisposal WP at 0 year of storage time under the same reference conditions. 
Table 6. Thermal/radiation properties of the direct codisposal canister components used for the present analysis.

\begin{tabular}{|c|c|c|c|c|}
\hline $\begin{array}{l}\text { Regions } \\
\text { in Fig. } 6\end{array}$ & \multicolumn{2}{|c|}{ Materials } & Thermal Conductivity & Emissivity \\
\hline & \multirow{2}{*}{$\begin{array}{l}\text { SNF } \\
\text { Canister }\end{array}$} & SNF Region & $34.60 \mathrm{~W} / \mathrm{m} \mathrm{K}$ & 一 \\
\hline & & Canister Wall & $17.30 \mathrm{~W} / \mathrm{m} \mathrm{K}$ & 0.60 \\
\hline & \multicolumn{2}{|c|}{$\begin{array}{l}\text { High-level Waste Glass Log } \\
\text { (HWGL) }\end{array}$} & $1.046 \mathrm{~W} / \mathrm{m} \mathrm{K}$ & 0.60 \\
\hline & \multirow{2}{*}{$\begin{array}{l}\text { Back-fille } \\
\text { Gas }\end{array}$} & Air & $0.036 \mathrm{~W} / \mathrm{m} \mathrm{K}$ & 一 \\
\hline & & Helium & $0.205 \mathrm{~W} / \mathrm{m} \mathrm{K}$ & 一 \\
\hline & \multicolumn{2}{|c|}{$\begin{array}{l}\text { Codisposal WP } \\
\text { Inner Wall }\end{array}$} & $10.977 \mathrm{~W} / \mathrm{m} \mathrm{K}$ & 0.80 \\
\hline & \multicolumn{2}{|c|}{$\begin{array}{l}\text { Codisposal WP } \\
\text { Outer Wall }\end{array}$} & $48.810 \mathrm{~W} / \mathrm{m} \mathrm{K}$ & - \\
\hline
\end{tabular}

From these results, radiative cooling mechanism is shown to be the most dominant cooling mode among the three cooling modes for higher than $130^{\circ} \mathrm{C}$ of the maximum package temperature although detailed cooling mechanisms are quite different each other. The package temperature gradients become small after 200 years (due to rapidly decaying power) and near 2000 years the temperatures become uniform at the ambient geological temperature.

Radial temperature distributions based on the baseline model are shown as a function of storage time in Fig. 10. Figure 11 also shows temperature contour plot over the entire computational domain for the reference conditions at 0 year of storage time. Although there is slight difference of the maximum package temperatures between the baseline model and the detailed model, the cooling mechanism of the detailed model is quite different from that of the baseline model since the baseline model neglects effects of buoyancy-driven natural circulation of back-filled gas inside the enclosed WP. Comparison of the two model results along the vertical centerline is shown in Fig. 12. The results from the detailed model show that the temperature at the top surface of the WP is about $10^{\circ} \mathrm{C}$ higher than the WP bottom temperature because hot gas tends to move upward due to the gravitational effect. On the other hand, the baseline model can not capture this physical behavior due to neglect of the natural convection mechanism even though it predicts the maximum temperature similar to that of the detailed model. Figure 13 shows radial temperature distributions performed by the two models along the near-horizontal line of SNF center to HWGL center (A-A' line shown in the same figure). 
From these results, temperature gradient across the HWGL region for the detailed model is much smaller than that of the baseline model due to the gas temperature mixing effect driven by the natural gas circulation inside the WP.

Figure 14 shows velocity vector plot over the flow domain of back-filled gas inside the direct codisposal WP for the reference conditions. Temperature contour plot corresponding to the velocity distribution of Fig. 14 is shown in Fig. 15. This information may be important in predicting the movement of humidity and condensate water sources around the surface of the WP container, which can be closely related to the corrosion/degradation model of the codisposal WP. The gas flow pattern over the entire flow domain within the WP container is illustrated in Fig. 16 from the computational results for the reference conditions (helium-cooled WP with bounding decay heat source).

The following key parameters were mainly considered to perform the sensitivity analysis for the codisposal WP design by using a parametric approach with respect to the reference conditions defined in Table 1:

- Back-filled Gas: When air or helium gas is used as back-filled gas for the SNF canister and the entire codisposal canister, maximum temperature for air-filled waste package at 0 year of storage time is about $160{ }^{\circ} \mathrm{C}$ higher than that of helium-filled package for bounding decay heat loads of Table 2 and natural convective boundary conditions with $100^{\circ} \mathrm{C}$ of repository ambient temperature. Comparison of the maximum temperatures computed by the baseline model for the helium-cooled and the air-cooled waste packages are shown in Table 7 . Figure 17 shows maximum temperature transients of the air-cooled direct codisposal WP based on the conduction model and the baseline model with bounding decay heat load for ambient temperature of $100^{\circ} \mathrm{C}$ during the first 2000 years of storage time. The results of the two models show that maximum temperatures drop rapidly with respect to storage time and then the package temperatures become nearly flat after about the first 1500 years of storage time.

Table 7. Comparison of maximum temperatures for helium-cooled and air-cooled direct codisposal waste packages with bounding heat source based on the baseline model for various storage times (ambient temperature $=100^{\circ} \mathrm{C}$ ).

\begin{tabular}{|c|c|c|}
\hline Storage Times (Years) & Helium-cooled WP (C) & Air-cooled WP $\left({ }^{\circ} \mathbf{C}\right)$ \\
\hline 0 & 304 & 466 \\
\hline 10 & 255 & 388 \\
\hline 50 & 172 & 234 \\
\hline 90 & 133 & 164 \\
\hline 190 & 109 & 119 \\
\hline 590 & 103 & 109 \\
\hline 1990 & 101 & 101 \\
\hline
\end{tabular}

- Decay Heat Loads: Transient decay heat sources for typical MIT-/ ORR-type SNF fuel canisters was estimated by using Monte Carlo code, SCALE 4.2 - ORIGEN. 
The decay heat loads for HWGL canisters was estimated based on the time of glass log canister production, assuming 5 year old sludge and 15 year old precipitate. The detailed methodology for the estimation of the decay heat loads are documented in Reference 1. Thus, the well-defined decay heat loads for the SNF canister and the HWGL of the direct codisposal WP were used for the present parametric analysis. The decay heat loads were estimated for bouncling low-enriched uranium (LEU) / high-enriched uranium (HEU) and nominal LEU/HEU types based on reactor fuel characterization. The present analysis selected conservative approach by using higher decay heat loads for the SNF and the HWGL regions. Figure 18 presents maximum temperature transients of air-cooled direct codisposal WP performed by the baseline model for bounding and nominal decay heat loads for selected times during the first 2000 years of storage times. From the results, the air-cooled codisposal WP with nominal decal heat load is about $120^{\circ} \mathrm{C}$ higher than the heliumcooled WP with bounding decay heat load. Figure 19 shows radial temperature distributions from the center of the SNF canister to the boundary region of the waste package as a function of selected storage time up to the first 1990 years of storage time. The numerical results are also shown in Table 8 . When the acceptance criterion for maximum temperature of the package is set to be $350^{\circ} \mathrm{C}$, the air-filled direct codisposal WP satisfies the acceptance criterion for the nominal decay heat load.

Table 8. Comparison of maximum temperatures for air-filled direct codisposal waste package with bounding and nominal decay heat loads based on the baseline model for various storage times (ambient temperature $=100^{\circ} \mathrm{C}$ ).

\begin{tabular}{|c|c|c|}
\hline $\begin{array}{l}\text { Storage Jimes } \\
\text { (Vears) }\end{array}$ & $\begin{array}{l}\text { Airfilled WP with Nominal } \\
\text { Decay Heat Loads }\end{array}$ & $\begin{array}{l}\text { Air filledy With Bounding } \\
\text { Becay Heat Loads }\end{array}$ \\
\hline 0 & 345 & 466 \\
\hline 10 & 287 & 388 \\
\hline 50 & 184 & 234 \\
\hline 90 & 146 & 164 \\
\hline 190 & 112 & 119 \\
\hline 590 & 102 & 109 \\
\hline 1990 & 101 & 101 \\
\hline
\end{tabular}

- Initial reference storage time related to the spent fuel cooling time before the emplacement of aluminum-clad DOE SNF assemblies into the WP container: This parameter is directly related to the peak temperature of the codisposal WP for given boundary conditions. The present analyses selected 10 years' cooling time as initial reference time, which was chosen as one of the reference conditions for the thermal performance analysis shown in Table 1. Table 9 shows peak temperatures of the direct codisposal WP for various cooling times (since the discharge of fuel from reactor core) before emplacement of spent fuel into the waste package container. These results were based on the baseline model for 100 and $150{ }^{\circ} \mathrm{C}$ of ambient temperatures and $1.5 \mathrm{~W} / \mathrm{m}^{2}{ }^{\circ} \mathrm{C}$ of the WP wall heat transfer coefficient. 
Table 9. Peak temperatures of the direct codisposal waste package with bounding decay heat loads using the baseline model under 100 and $150^{\circ} \mathrm{C}$ ambient temperatures for various cooling times.

\begin{tabular}{|c|c|c|c|}
\hline 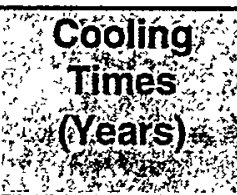 & 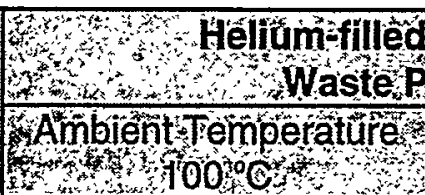 & 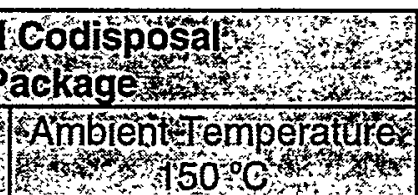 & 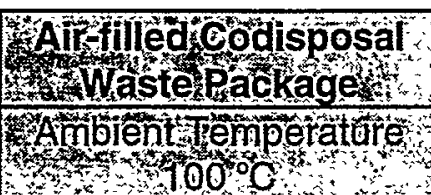 \\
\hline 10 & 304 & 348 & 466 \\
\hline 20 & 255 & 309 & 388 \\
\hline 60 & 172 & 225 & 234 \\
\hline
\end{tabular}

- Internal Conduction Path Between the SNF and HWGL Canisters: The present model does not consider internal conduction path because of limited computational time available, but the future model will consider the internal structure of the codisposal WP.

- Repository Temperature History: The temperature history of a repository is closely related to total heat loads of the waste package in a repository and the ambient geological conditions surrounding the waste package. The reasonably accurate model is not available now. Consequently, the present studies were performed over a range of possible repository temperature conditions $\left(50^{\circ} \mathrm{C}\right.$ to $\left.200^{\circ} \mathrm{C}\right)$. Figure 20 presents peak temperature transients of helium-cooled direct codisposal WP with bounding decay heat loads using the baseline and the conduction models for two typical ambient temperatures of 100 and $150{ }^{\circ} \mathrm{C}$ during the first 2000 years of storage time. Table 10 also shows peak temperatures of the helium-cooled direct codisposal WP for the two geological ambient temperatures. Figure 21 shows peak temperatures with respect to ambient repository temperatures for two different backfilled gases, corresponding to helium-filled and air-filled codisposal waste packages at year 0 of storage time. The results of the baseline model indicated that the predicted peak temperature of the waste package increases almost linearly with ambient repository temperature as shown in Fig. 21. In reality, geological ambient temperature surrounding the WP is dependent on all aspects of emplacement methods of the waste packages in a repository, waste forms, and geological conditions such as groundwater reservoir or soil/tunnel humidity, etc. In the future work, a model to include the geological media and to consider the impact of neighboring tunnels or waste packages need to be developed to provide the best estimate thermal boundary conditions to the present model. 
Table 10. Comparison of maximum temperatures for helium-filled direct codisposal waste package with bounding decay heat loads using the baseline model under 100 and $150^{\circ} \mathrm{C}$ ambient temperatures for various storage times.

\begin{tabular}{|c|c|c|c|c|}
\hline 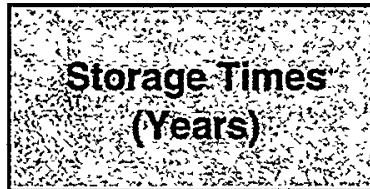 & $\begin{array}{r}\text { Ambientiemp } \\
\text { Modseline } \\
\text { Model }\end{array}$ & $\begin{array}{l}\text { eratureofwh } \\
\text { oc- } \\
\text { Conducton } \\
\text { Model }\end{array}$ & 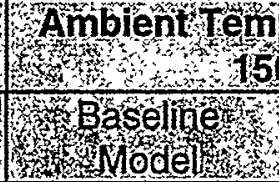 & 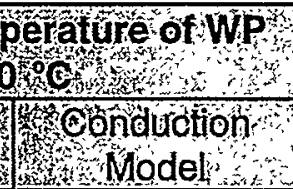 \\
\hline 0 & 304 & 425 & 348 & 475 \\
\hline 10 & 255 & 355 & 309 & 404 \\
\hline 50 & 172 & 209 & 225 & 259 \\
\hline 90 & 133 & 151 & 181 & 201 \\
\hline 190 & 109 & 114 & 160 & 165 \\
\hline 590 & 103 & 105 & 153 & 155 \\
\hline 1990 & 101 & 101 & 151 & 151 \\
\hline
\end{tabular}

From the present thermal performance analyses, it was found that the air-filled codisposal WP has much steeper temperature gradient at the gas-solid interface than the helium-filled codisposal WP does. This is mainly due to the difference of the thermal conductivity values, that is, $\nabla \mathrm{T}=\mathrm{q}^{\prime \prime} / \mathrm{k}$. As shown in Fig. 12, temperature gradient at the gas-solid interface becomes much steeper due to the formation of thermal boundary layer near the solid wall region when natural convection effect is included. This phenomenon is consistent with the literature data (Ref. 9)

It is also noted that the peak temperature location of the waste package is moved from the central edge of the HWGL region to the SNF region as decay heat load for the central SNF canister increases for a given heat load in HWGL (see Ref. 11). The graphical results for the radial temperature distributions within the package were shown as function of SNF decay heat loads for a given decay heat load of the HWGL region of the codisposal WP in the previous report (see Fig. 4.19 in Ref. 11). 


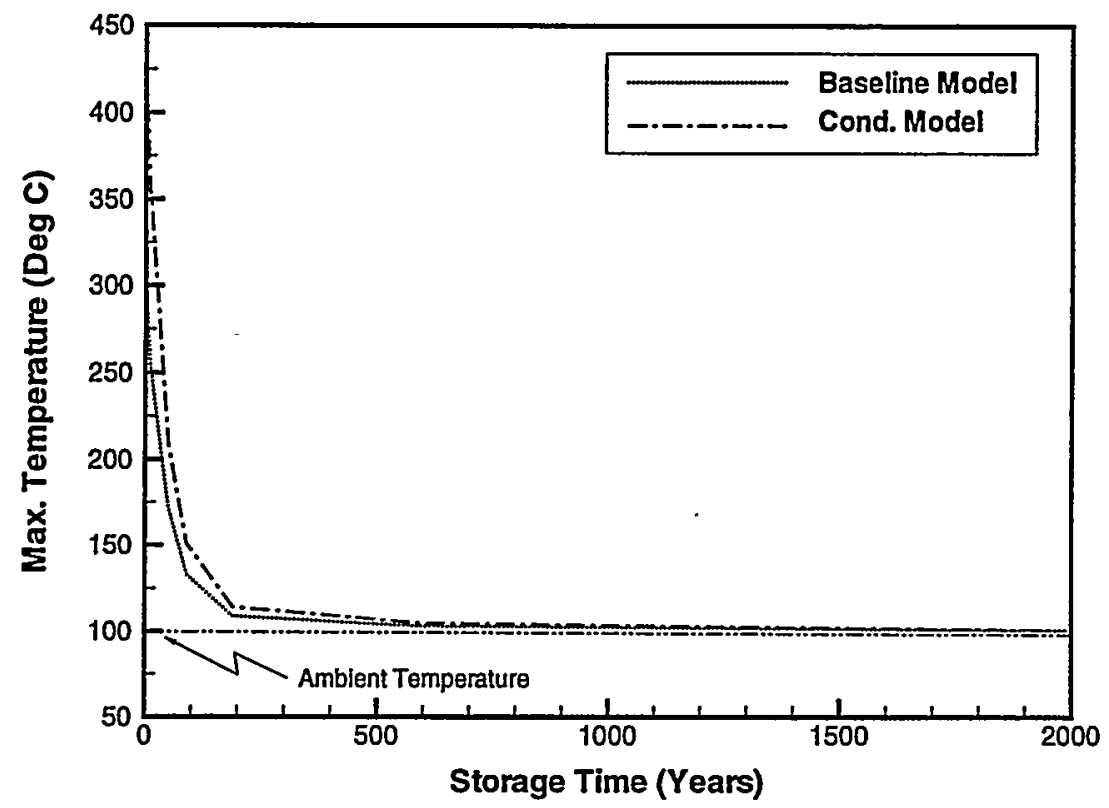

Figure 9. Maximum temperature of helium-cooled direct codisposal WP with bounding SNF decay heat source for baseline and conduction models as a function of storage time. 

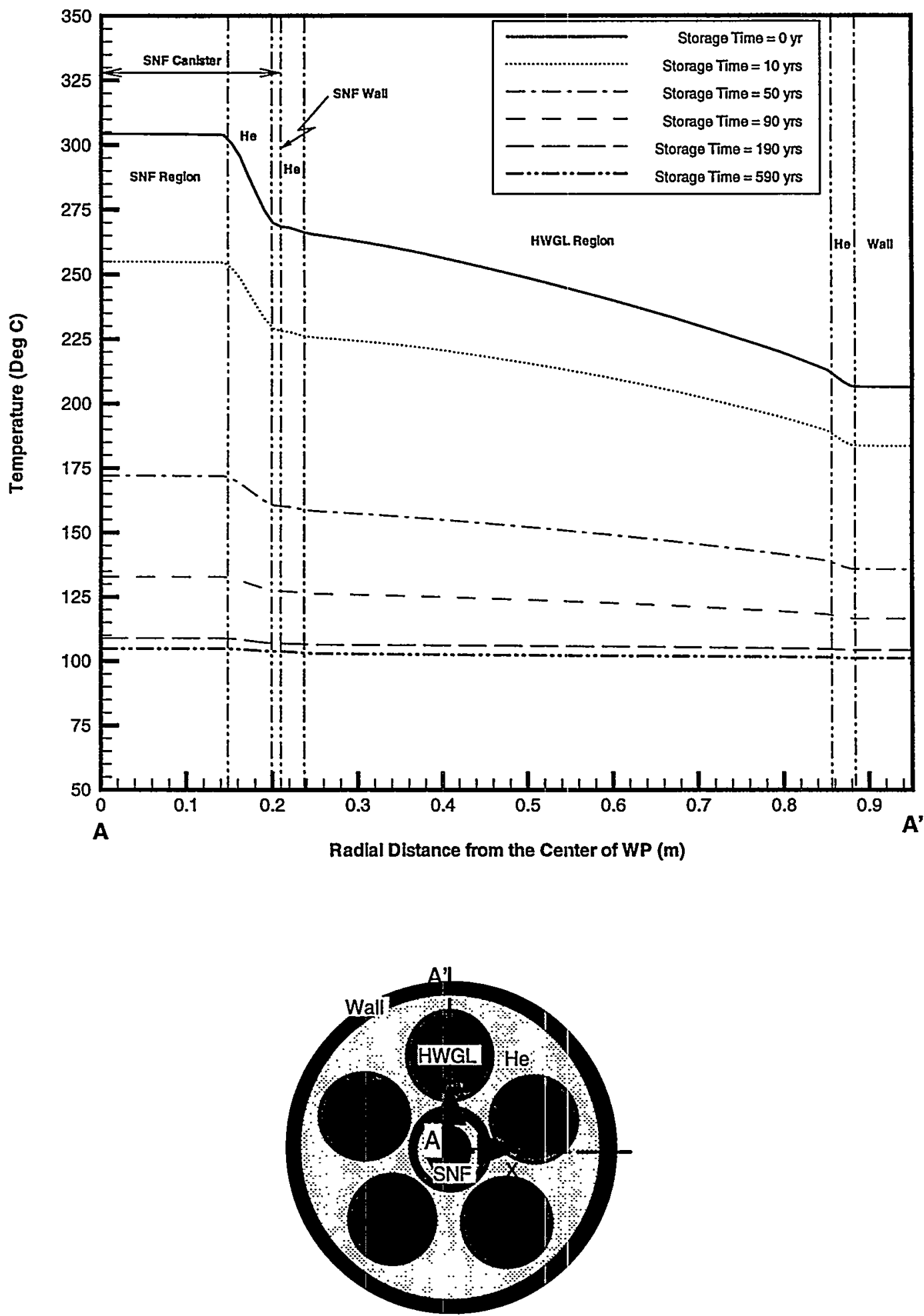

Figure 10. He-cooled direct codisposal WP temperature distribution for various storage times based on baseline model with bounding SNF decay heat source. 
Temperature (K)

$5.7747 \mathrm{E}+02$

$5.6112 \mathrm{E}+02$

$5.4476 \mathrm{E}+02$

$5.2841 \mathrm{E}+02$

$5.1205 E+02$

$4.9570 E+02$

$4.7934 \mathrm{E}+02$

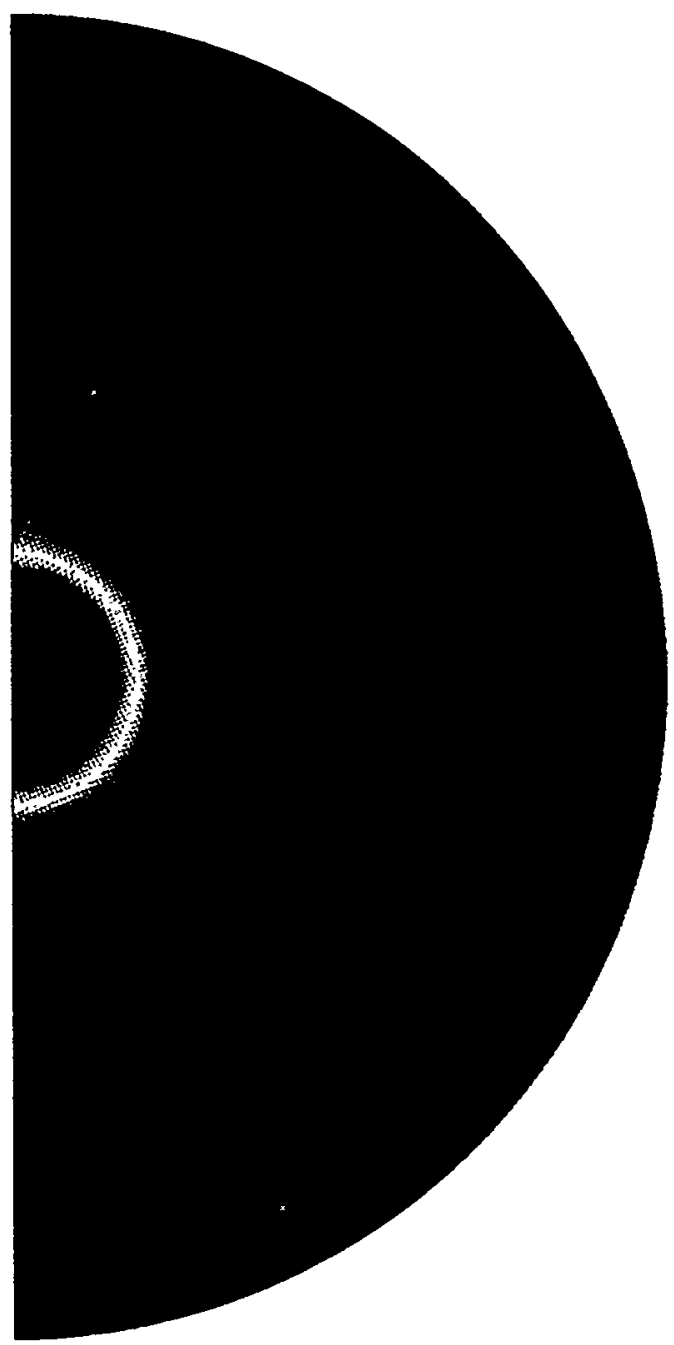

Figure 11. Temperature contour plot based on the baseline model for helium-cooled direct codisposal WP with bounding decay heat source at 0 years of storage time. 

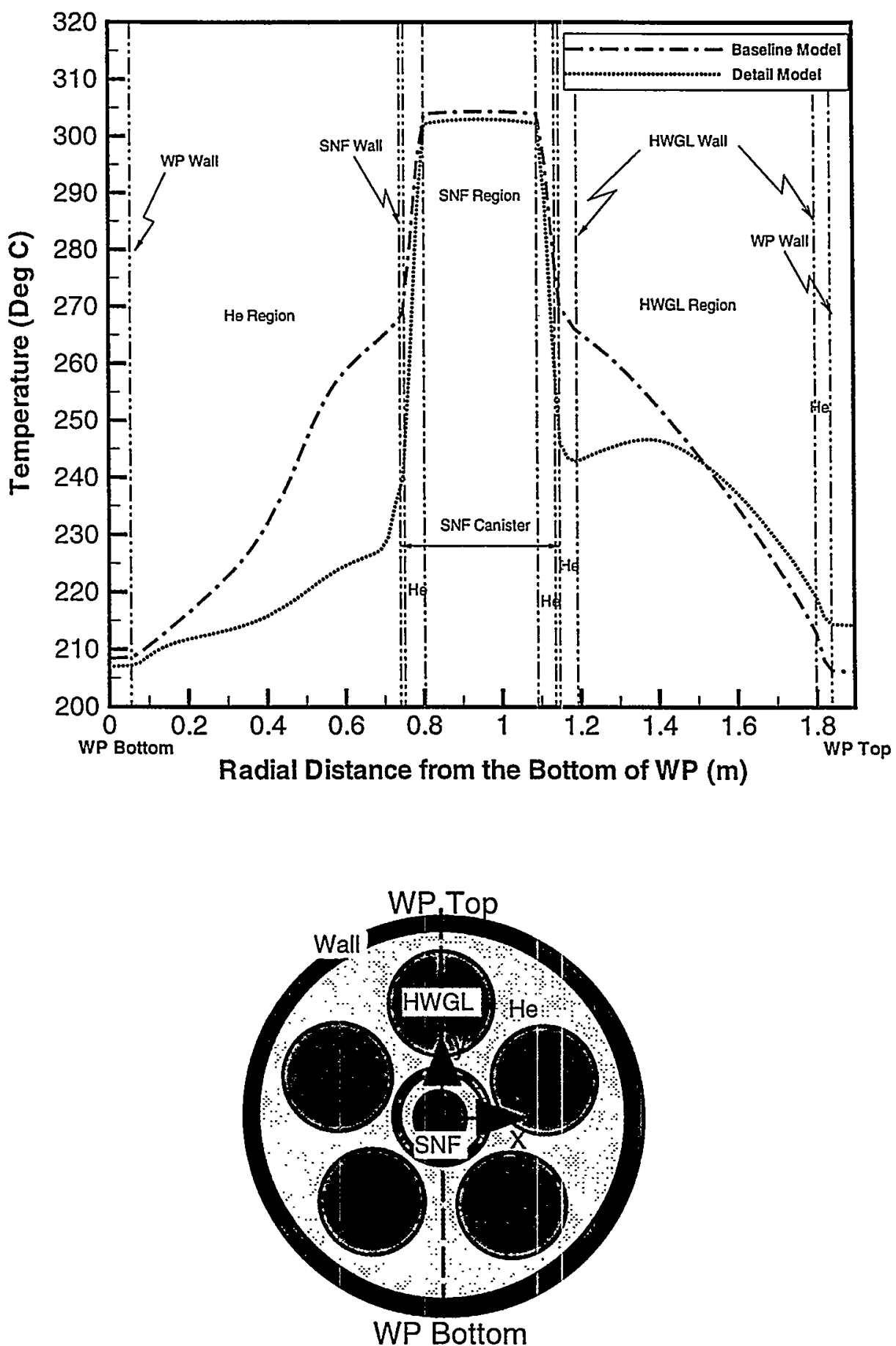

Figure 12. Comparison of centerline temperature distributions based on the baseline model and the detailed model for helium-cooled direct codisposal WP with bounding decay heat source. 

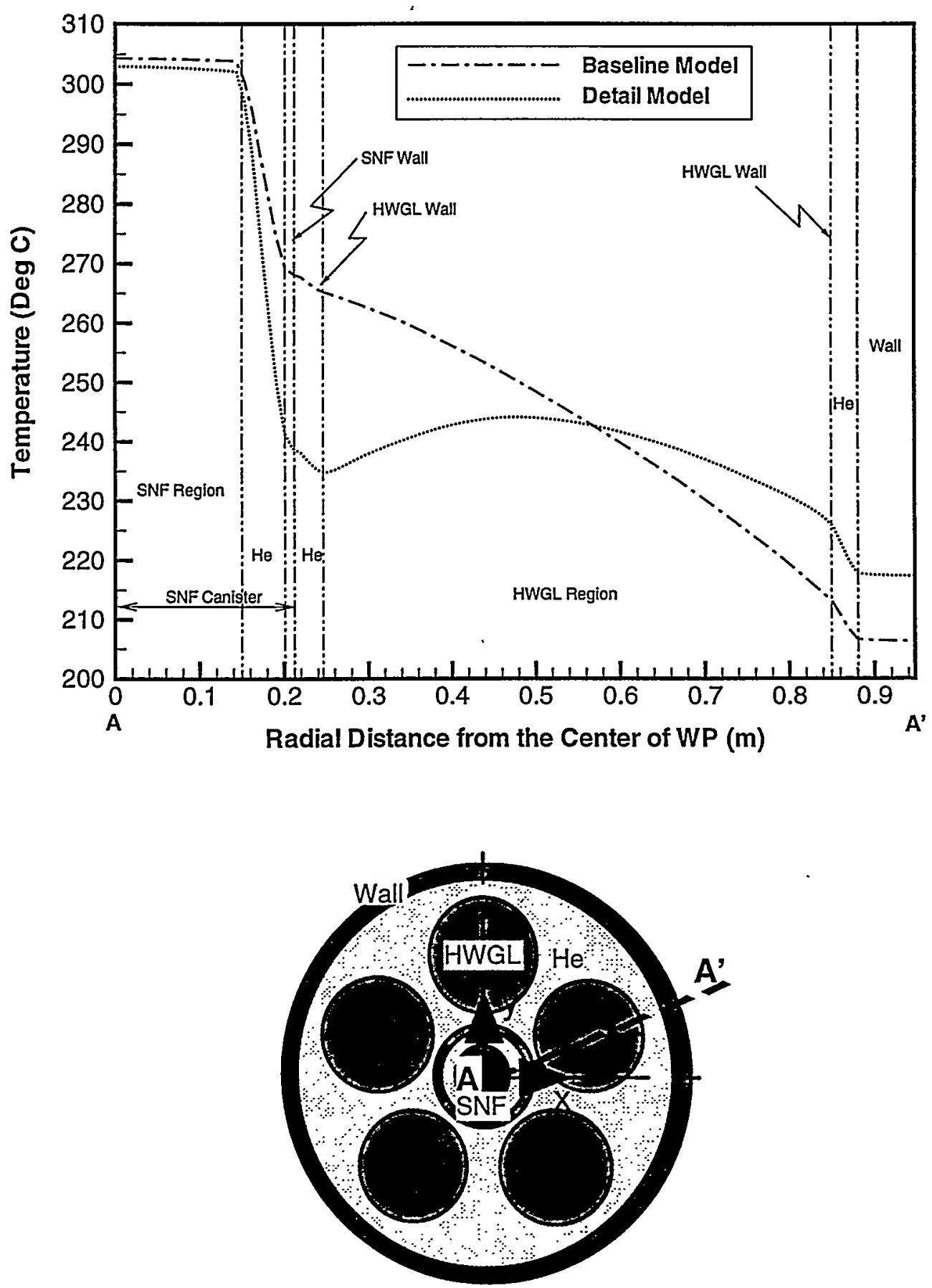

Figure 13. Comparison of temperature distributions based on the baseline model and the detailed model for helium-cooled direct codisposal WP with bounding decay heat source. 


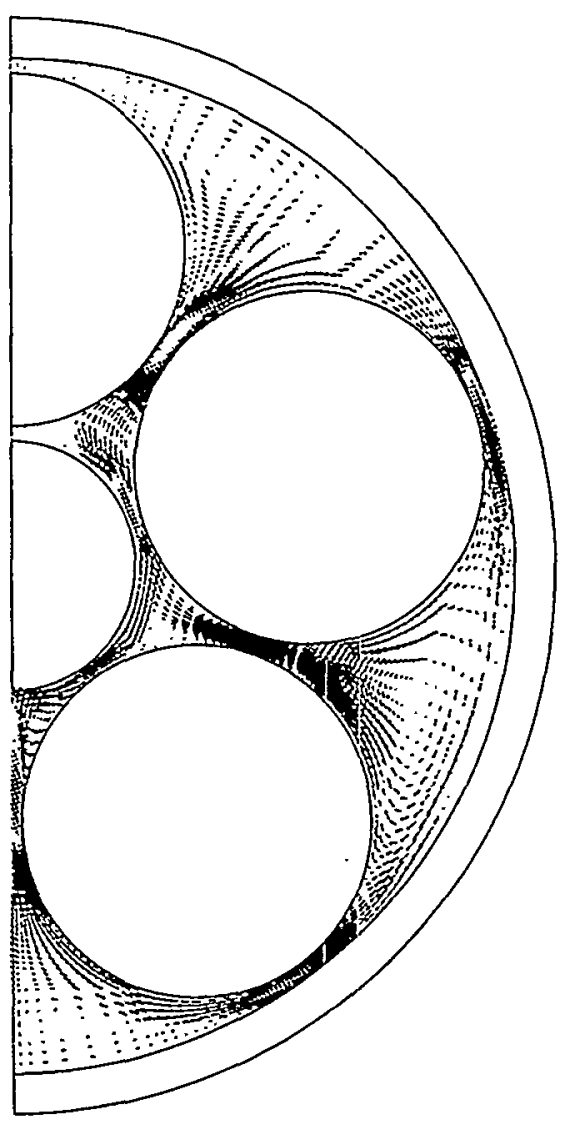

Conduction, Convection, and Radiation Model for He-cooled WP (Storage Time = 0

Figure 14. Velocity vector plot of back-filled gas based on the detailed model for heliumcooled direct codisposal WP with bounding decay heat source at 0 years of storage time. 


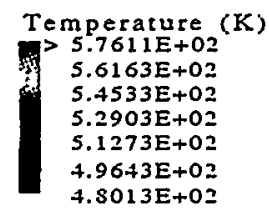

Conduction, Convection, and Radiation Model for He-cooled WP (Storage Time =

Figure 15. Temperature contour plot over the entire computational domain based on the detailed model for helium-cooled direct codisposal WP with bounding decay heat source at 0 years of storage time. 


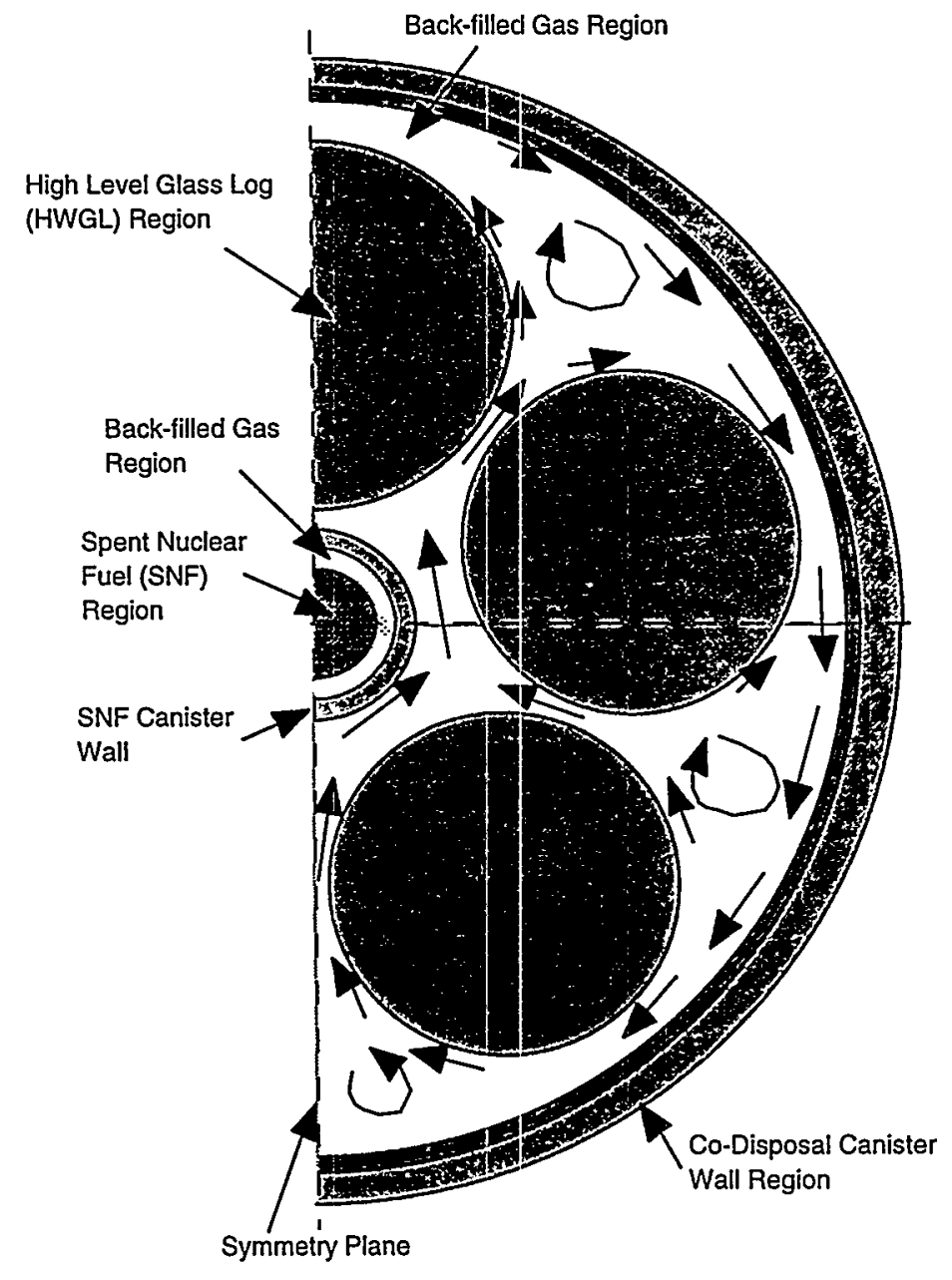

Figure 16. Back-filled gas flow pattern due to natural convective cooling within codisposal waste package. 


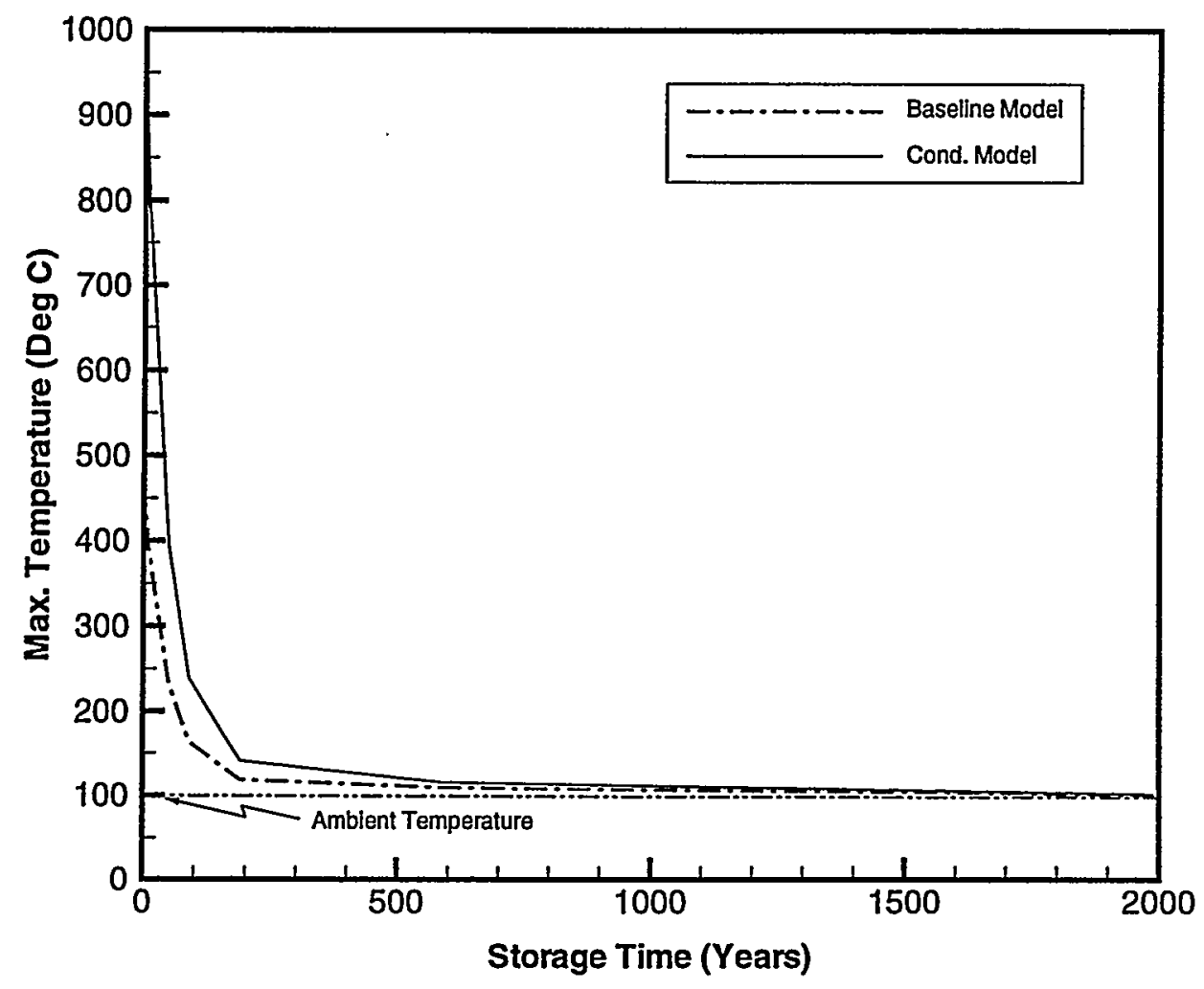

Figure 17. Maximum temperature of air-cooled direct codisposal WP for the baseline and the conduction models with bounding SNF decay heat source and ambient temperature of $100^{\circ} \mathrm{C}$ as a function of storage time. 


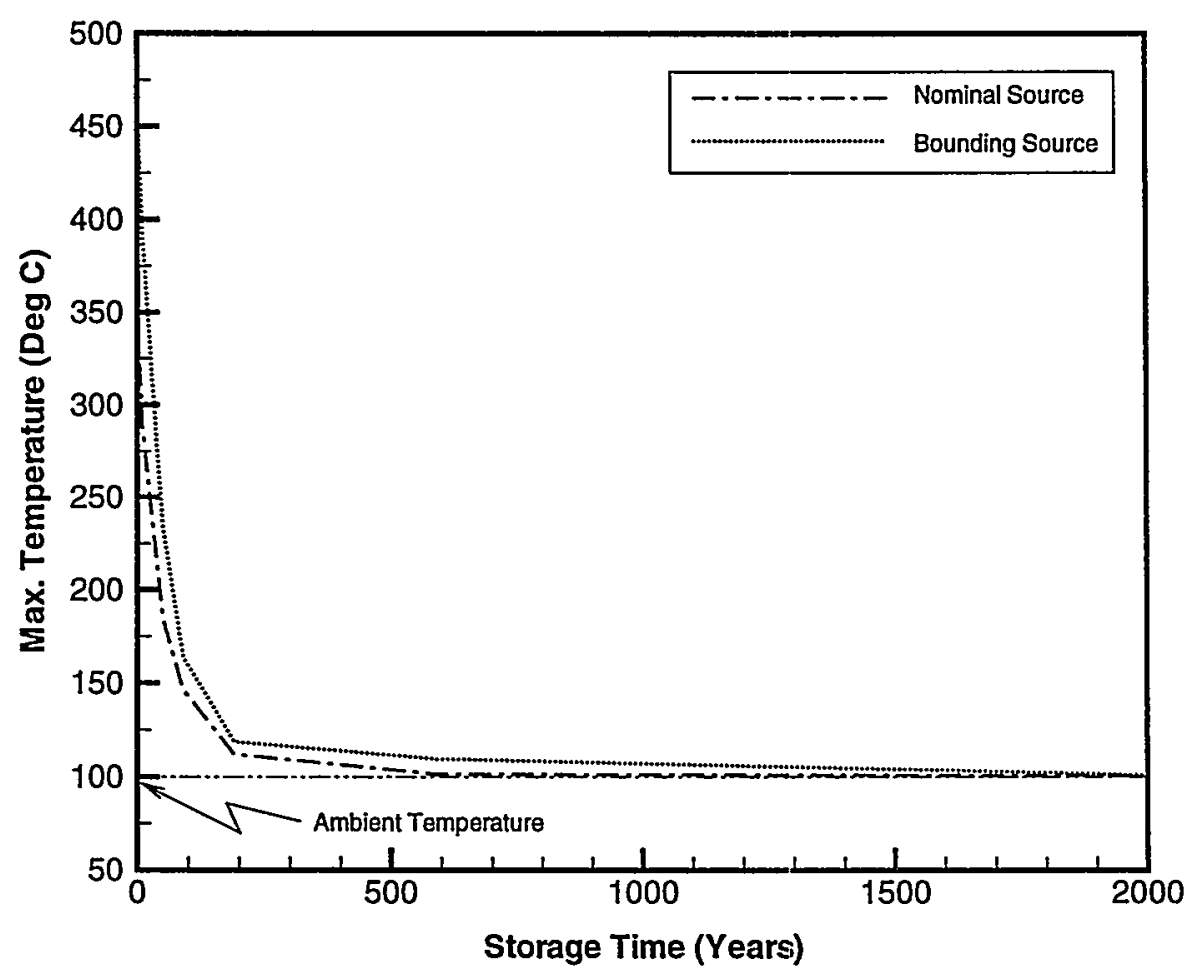

Figure 18. Comparison of maximum temperatures of air-cooled direct codisposal waste packages with bounding and nominal decay heat sources as a function of storage time based on the baseline model. 


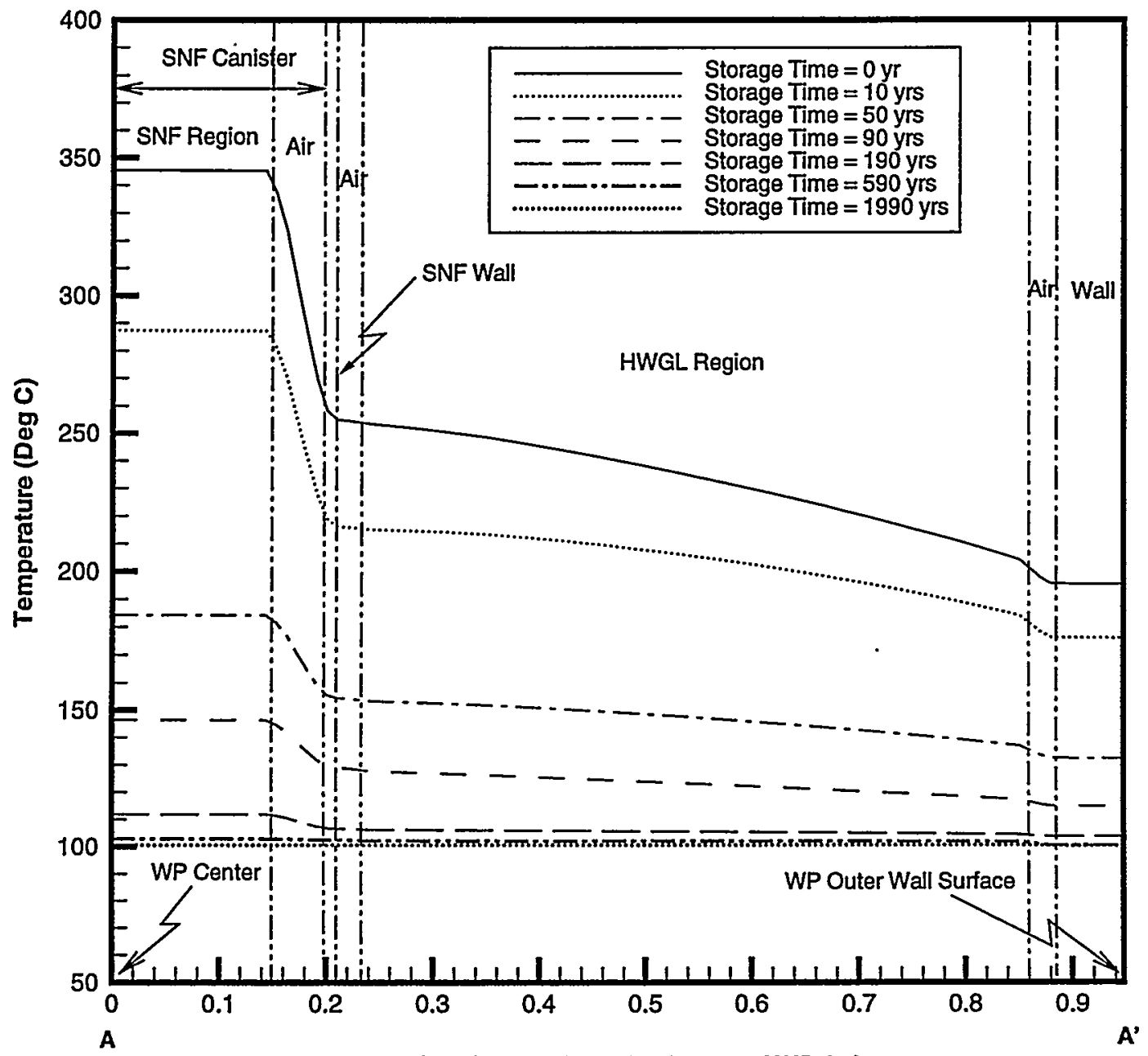

Radial Distance from the Center of WP (m)

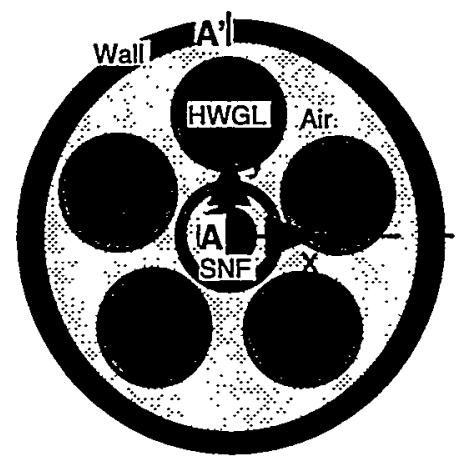

Figure 19. Temperature distribution of air-cooled direct codisposal waste package with nominal decay heat source as a function of storage time based on the baseline model. 


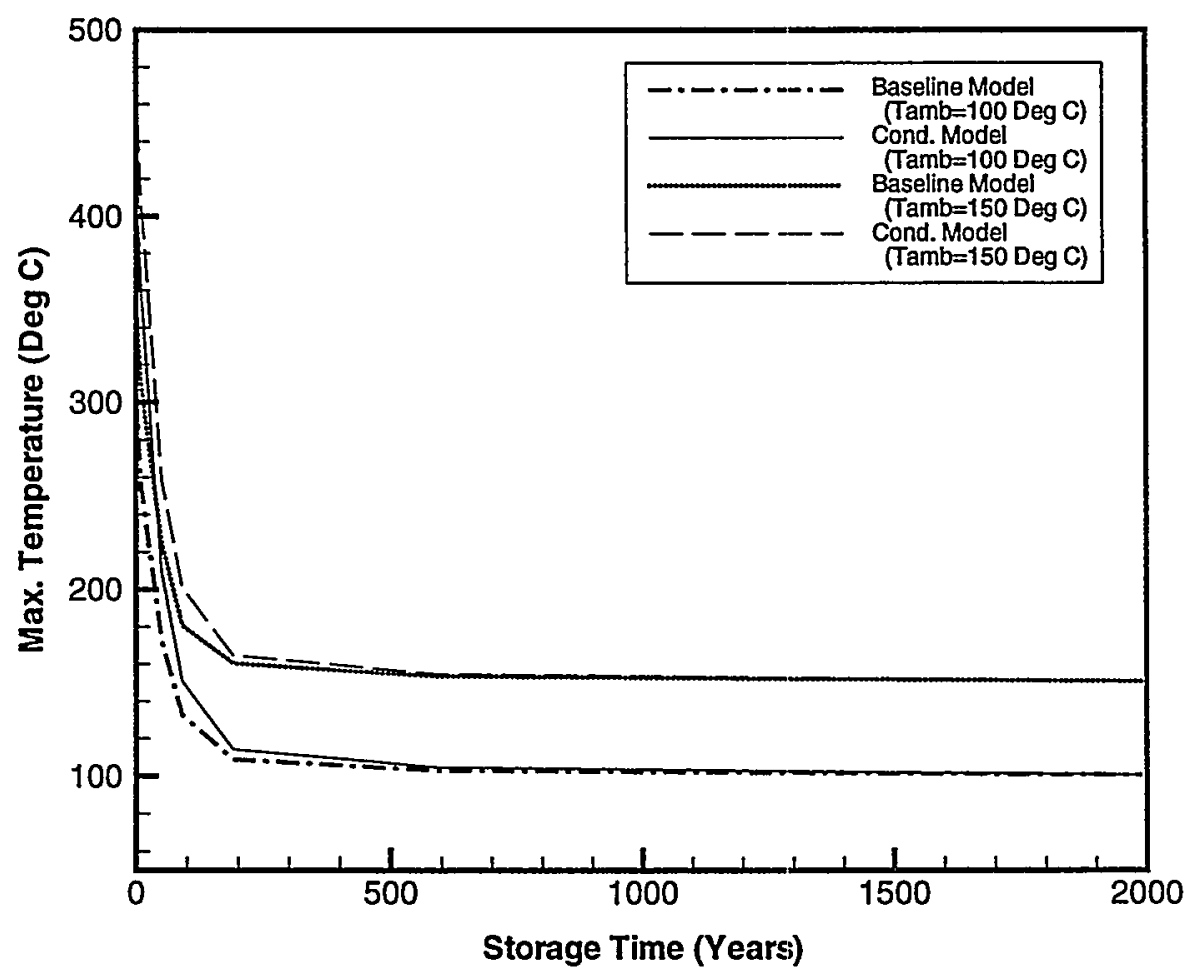

Figure 20. Maximum temperature of helium-cooled direct codisposal WP with bounding SNF decay heat source for the baseline and the conduction models with ambient temperatures of 100 and $150^{\circ} \mathrm{C}$ as a function of storage time. 


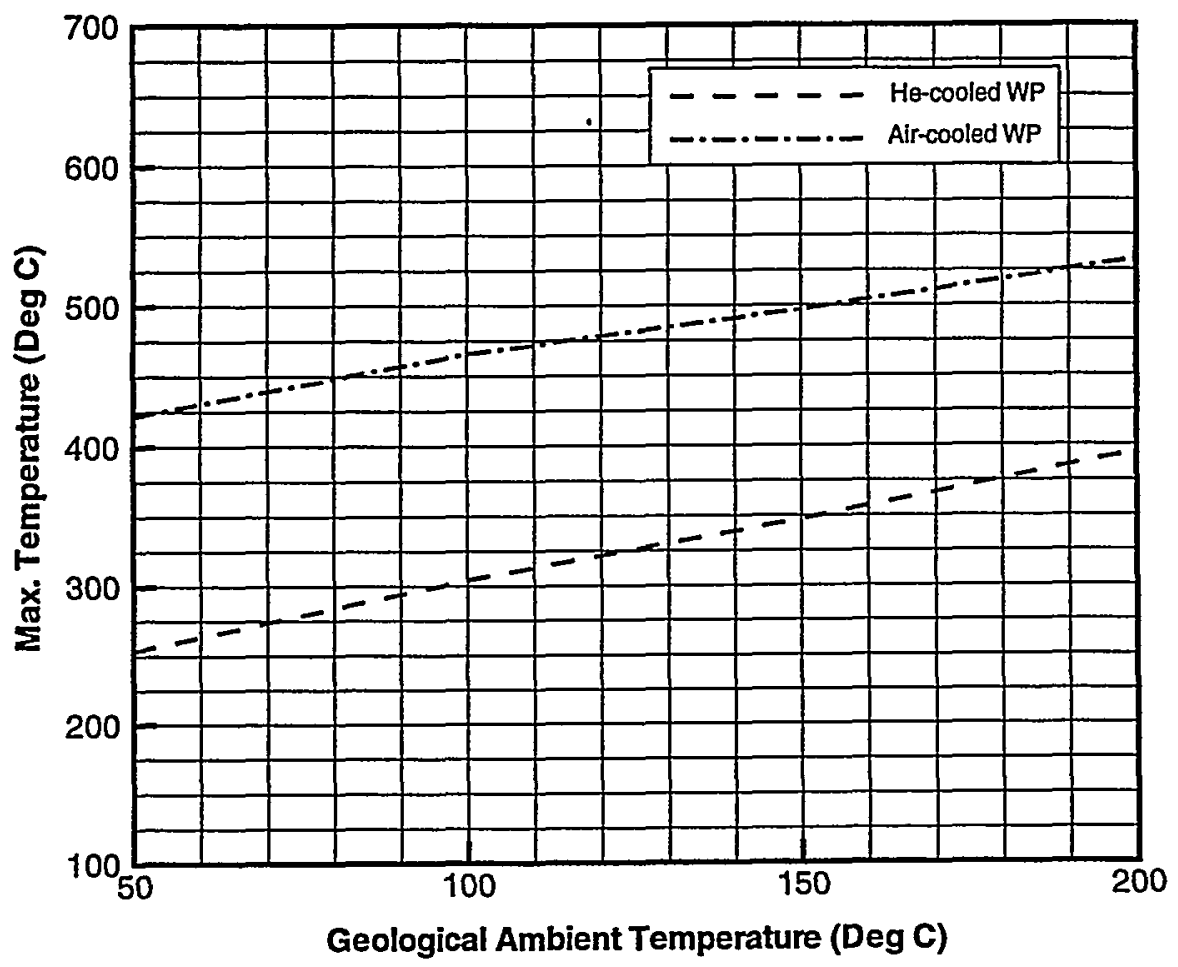

Figure 21. Maximum temperatures of air-cooled and helium-cooled direct codisposal waste packages with bounding SNF decay heat loads for various geological ambient temperatures. 


\subsection{Melt-Dilute Al-SNF Form Option}

Aluminum-clad DOE SNF disposition by the melt-dilute technique is one of the alternate SNF treatment technology options. For this option, the aluminum based highly enriched uranium will be melted and diluted with U-238 to reduce the U-235 enrichment to 10 to $20 \%$. In the melt-dilute disposition option, decay heat loads of the SNF canister of the codisposal WP will be dependent on how many assernblies will be melted and diluted in a DOE SNF canister. The majority of these assemblies will be Material Test Reactor (MTR) type such as aluminum-clad fuel. The decay heat source per each assembly processed in the melt-dilute option is slightly lower than for assembly in the direct disposal option since melting will release all of the $\mathrm{Kr}-85$ and some fraction of cesium isotopes, $\mathrm{Cs}-134$ and $\mathrm{Cs}-137$ including $\mathrm{Ba}_{\mathrm{m}}-137$ daughter product. Decay heat source for HWGL will be the same as that of the direct disposal option. The detailed methodology for the estimation of decay heat loads in the SNF canister of the melt-dilute disposition option used in this analysis is documented in Reference 1. The heat source term for other cases of melt-dilute forms are being developed and will be analyzed in the future.

The thermal performance analysis of the melt-dilute codisposal WP was performed mainly by using the baseline model for the reference design conditions defined in Table 1. The analysis for the air-cooled WP was also performed at the initial storage time. For the present analysis, two cases are considered for the helium-cooled codisposal WP with bounding decay heat load and $100^{\circ} \mathrm{C}$ ambient temperature of a repository using the reference conditions. One of the two cases considered here is the SNF canister filled with 75 vol.\% of melt-dilute ingot corresponding to 101 fuel assemblies, and the other one is the canister filled with 90 vol.\% of the ingot corresponding to 121 fuel assemblies. Both of them are $20 \%$ enriched alloy ingot containing the composition of aluminum-13.2 wt.\% uranium. Table 11 shows thermal and radiation properties of the codisposal package components containing melt-dilute disposition ingot, which were used for the present analysis (Ref. 6).

The radial temperature distribution results of the coclisposal WP for the 75 vol.\% SNF case are shown in Fig. 22. Peak temperature at initial storage time ("0" year) is about $285^{\circ} \mathrm{C}$, and surface temperature of the WP is about $207^{\circ} \mathrm{C}$ at zero year. Temperature gradients across the helium gas regions are much steeper than those of the other regions during the first 50 years of storage times. After 600 years of storage time, temperature of the WP actually becomes uniform over the entire region of the package. Figure 23 also presents temperature contour plot over the entire computational domain for the 75 vol. \% case at initial storage time.

Figure 24 shows the radial temperature distributions for the 90 vol.\% case along the A$A^{\prime}$ line shown in the same figure as a function of storage time. The results shows that temperature gradients for the 75 vol.\% case is generally larger through the entire years of storage period than those of the $90 \mathrm{vol} . \%$ case for the same boundary conditions since metal region for the 90 vol.\% of the SNF canister is larger than for the 75 vol.\% case. Temperature contour plot for the 90 vol.\% case is shown in Fig. 25 . Table 12 presents quantitative comparison of peak temperature transients between the $75 \mathrm{vol} . \%$ case and the $90 \mathrm{vol} \%$ case for selected times during the first 2000 years of storage time. Figure 26 also shows graphical comparison of the two different melt-dilute cases. 
Table 11. Thermal/radiation properties of the melt-dilute codisposal canister components used for the present analysis (Ref. 6).

\begin{tabular}{|c|c|c|c|c|}
\hline $\begin{array}{l}\text { Regions } \\
\text { in Fig. } 6\end{array}$ & \multicolumn{2}{|c|}{ Materials } & Thermal Conductivity & Emissivity \\
\hline & \multirow{2}{*}{$\begin{array}{l}\text { SNF } \\
\text { Canister }\end{array}$} & $\begin{array}{l}\text { Melt-Dilute } \\
\text { Region }\end{array}$ & $175.20 \mathrm{~W} / \mathrm{m} \mathrm{K}$ & - \\
\hline & & Canister Wall & $17.30 \mathrm{~W} / \mathrm{m} \mathrm{K}$ & 0.60 \\
\hline & \multicolumn{2}{|c|}{$\begin{array}{l}\text { High-level Waste Glass Log } \\
\text { (HWGL) }\end{array}$} & $1.046 \mathrm{~W} / \mathrm{m} \mathrm{K}$ & 0.60 \\
\hline & \multicolumn{2}{|c|}{ Back-filled Gas - Helium } & $0.205 \mathrm{~W} / \mathrm{m} \mathrm{K}$ & 一 \\
\hline & \multicolumn{2}{|c|}{$\begin{array}{l}\text { Codisposal WP } \\
\text { Inner Wall }\end{array}$} & $10.977 \mathrm{~W} / \mathrm{m} \mathrm{K}$ & 0.80 \\
\hline & \multicolumn{2}{|c|}{$\begin{array}{c}\text { Codisposal WP } \\
\text { Outer Wall }\end{array}$} & $48.810 \mathrm{~W} / \mathrm{m} \mathrm{K}$ & - \\
\hline
\end{tabular}

Table 12. Comparison of peak temperatures for the melt-dilute codisposal WP with bounding decay heat loads based on the baseline model for various storage times (ambient temperature $=100^{\circ} \mathrm{C}$ ).

\begin{tabular}{|c|c|c|}
\hline Storage Times & Melt Dilúte WP $(75$ vol. $\%)$ & Melt-Dilứte WP ( 90 vol. $\%)$ \\
\hline (Years) & He-filled $\mathrm{P}$, & o He filled WP \\
\hline 0 & $284\left(347^{\star}\right)$ & $264\left(286^{\star}\right)$ \\
\hline 10 & 247 & 238 \\
\hline 50 & 168 & 168 \\
\hline 90 & 135 & 133 \\
\hline 190 & 115 & 107 \\
\hline 590 & 104 & 101 \\
\hline 1990 & 102 & 100 \\
\hline
\end{tabular}

Note: * Peak temperature for the air-filled WP. 

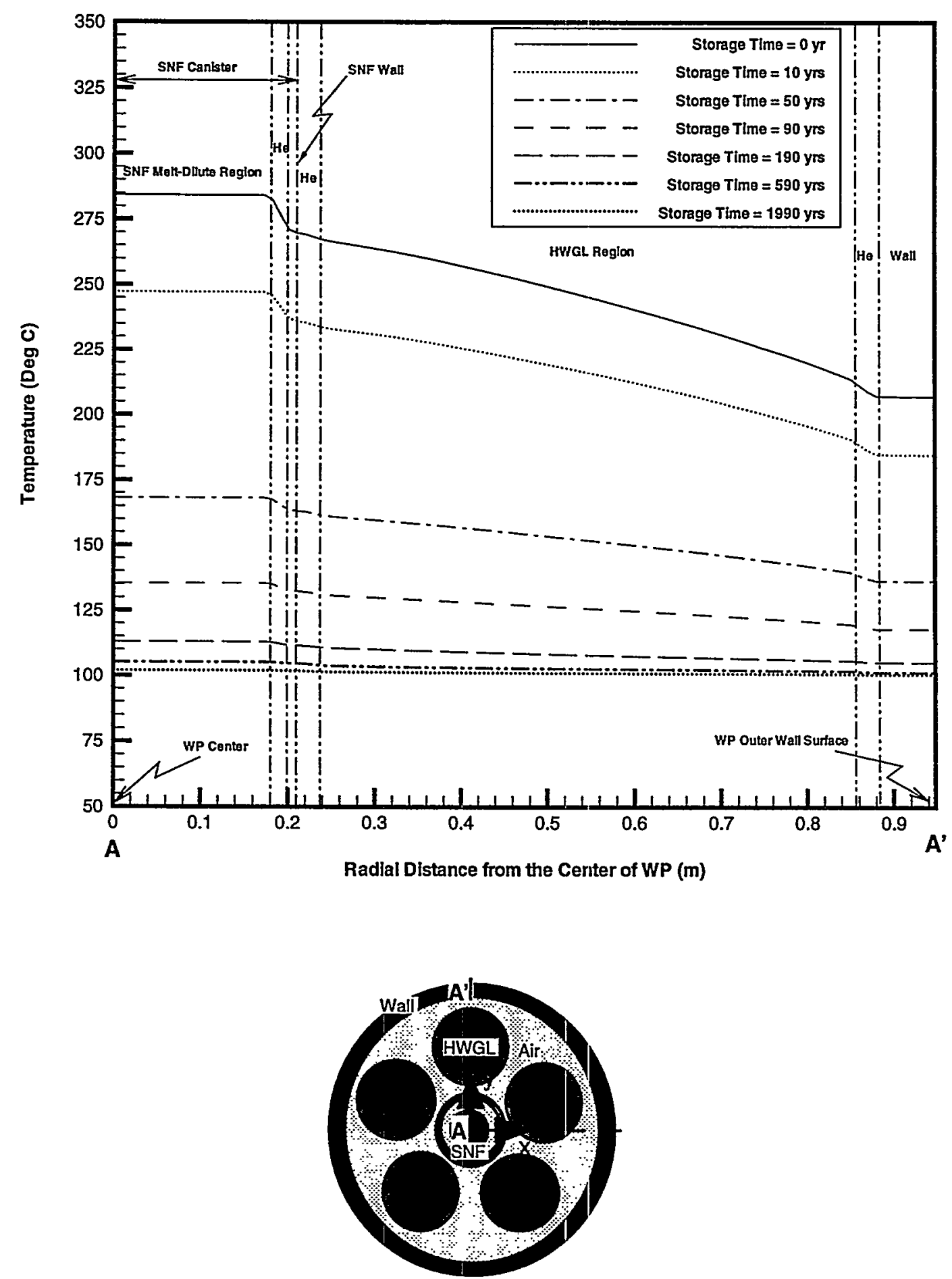

Figure 22. He-cooled $75 \%$ volume melt-dilute codisposal WP temperature distribution for various storage times based on the baseline model. 
Temperature (K)

$5.5742 E+02$

$5.3162 \mathrm{E}+02$

$5.1873 \mathrm{E}+02$

$5.0583 \mathrm{E}+02$

$4.9293 \mathrm{E}+02$

$4.8004 E+02$

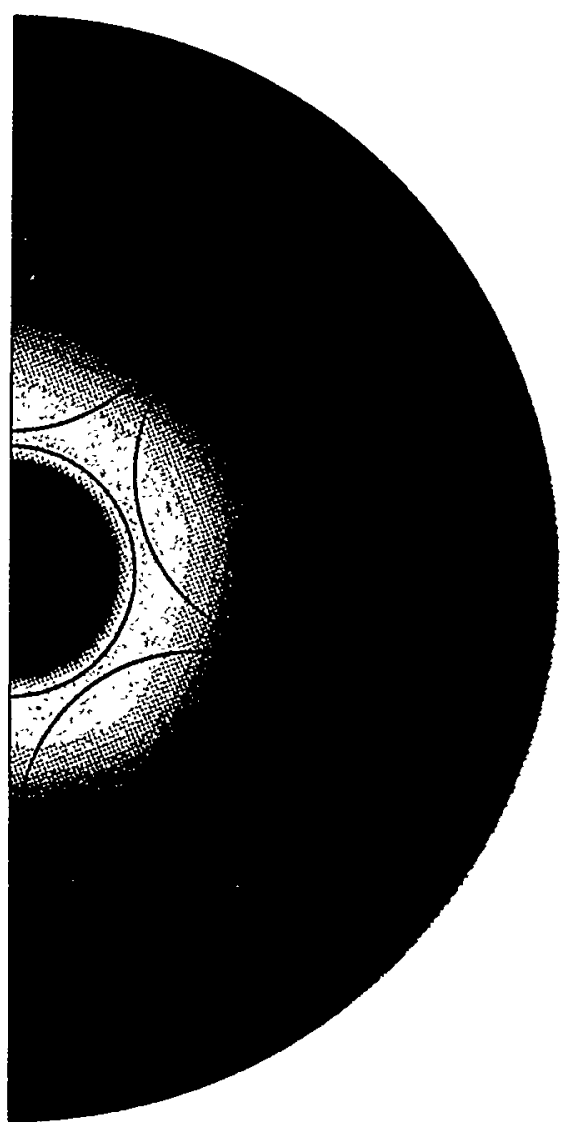

75 vol.\% Melt-Dilute at time = o year

Figure 23. Temperature contour plot for He-cooled $75 \%$ volume melt-dilute codisposal WP based on the baseline model at 0 years of storage time. 

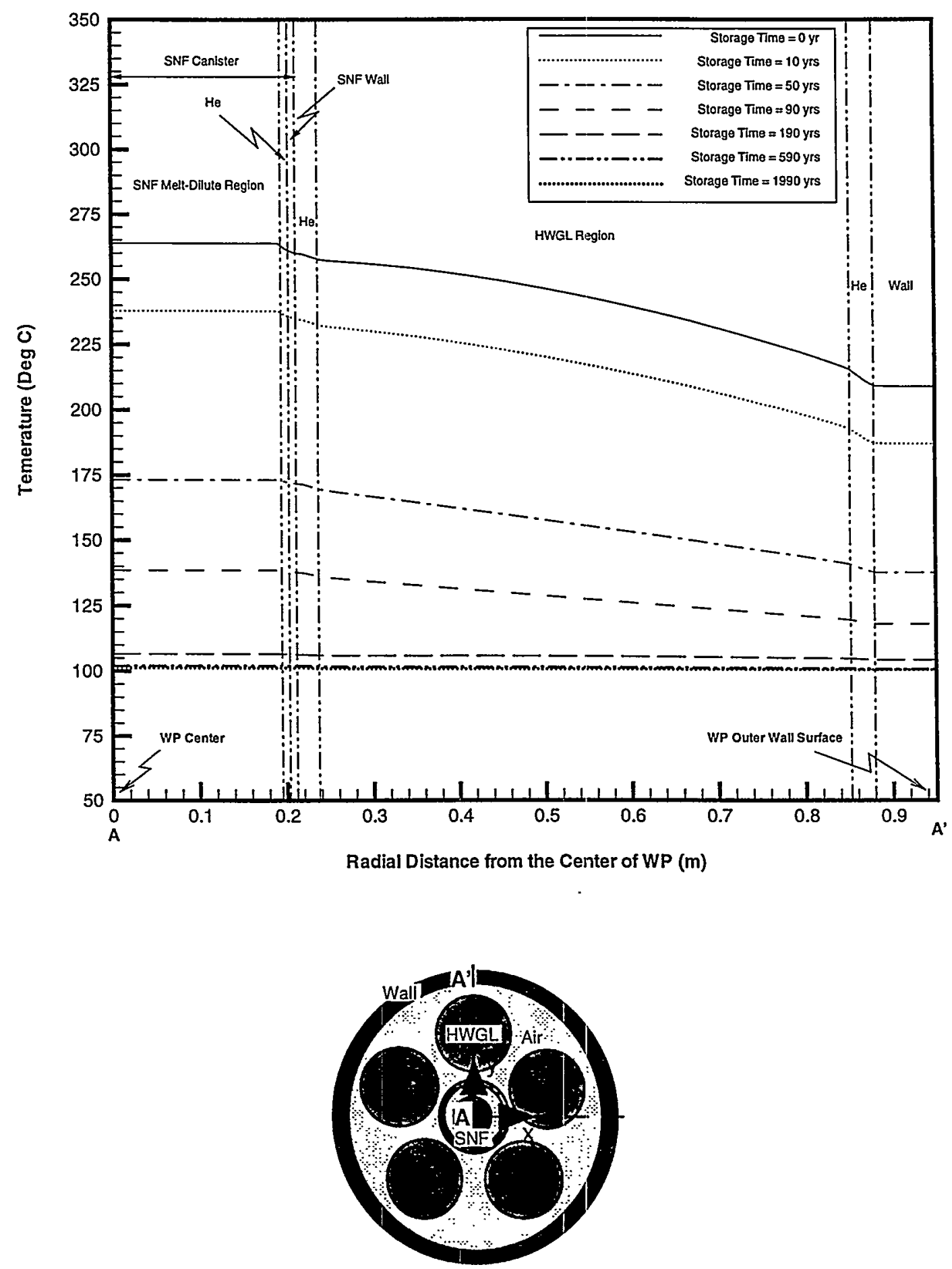

Figure 24. Radial temperature distribution of He-cooled $90 \%$ volume melt-dilute codisposal WP for various storage times based on the baseline model. 
Temperature (K)

- $5.3699 \mathrm{E}+02$

5.2779E+02

$5.1859 E+02$

$5.0939 E+02$

$5.0019 \mathrm{E}+02$

$4.9100 \mathrm{E}+02$

$4.8180 \mathrm{E}+02$

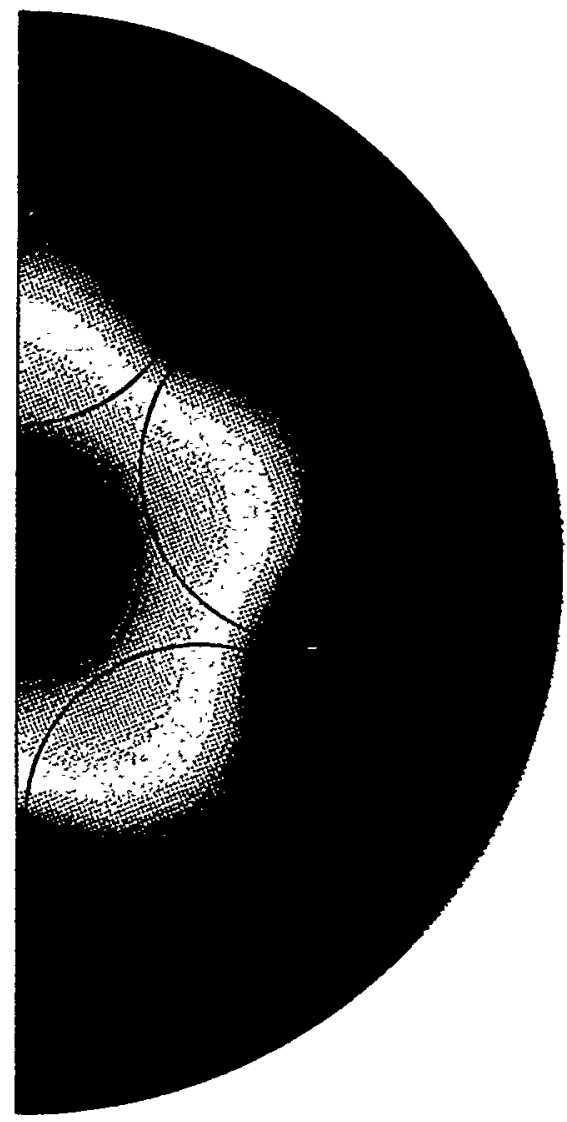

90 vol.\% Helium-filled Melt-Dilute at time $=0$ year

Figure 25. Temperature contour plot for helium-cooled $90 \%$ volume melt-dilute codisposal WP based on the baseline model at 0 years of storage time. 


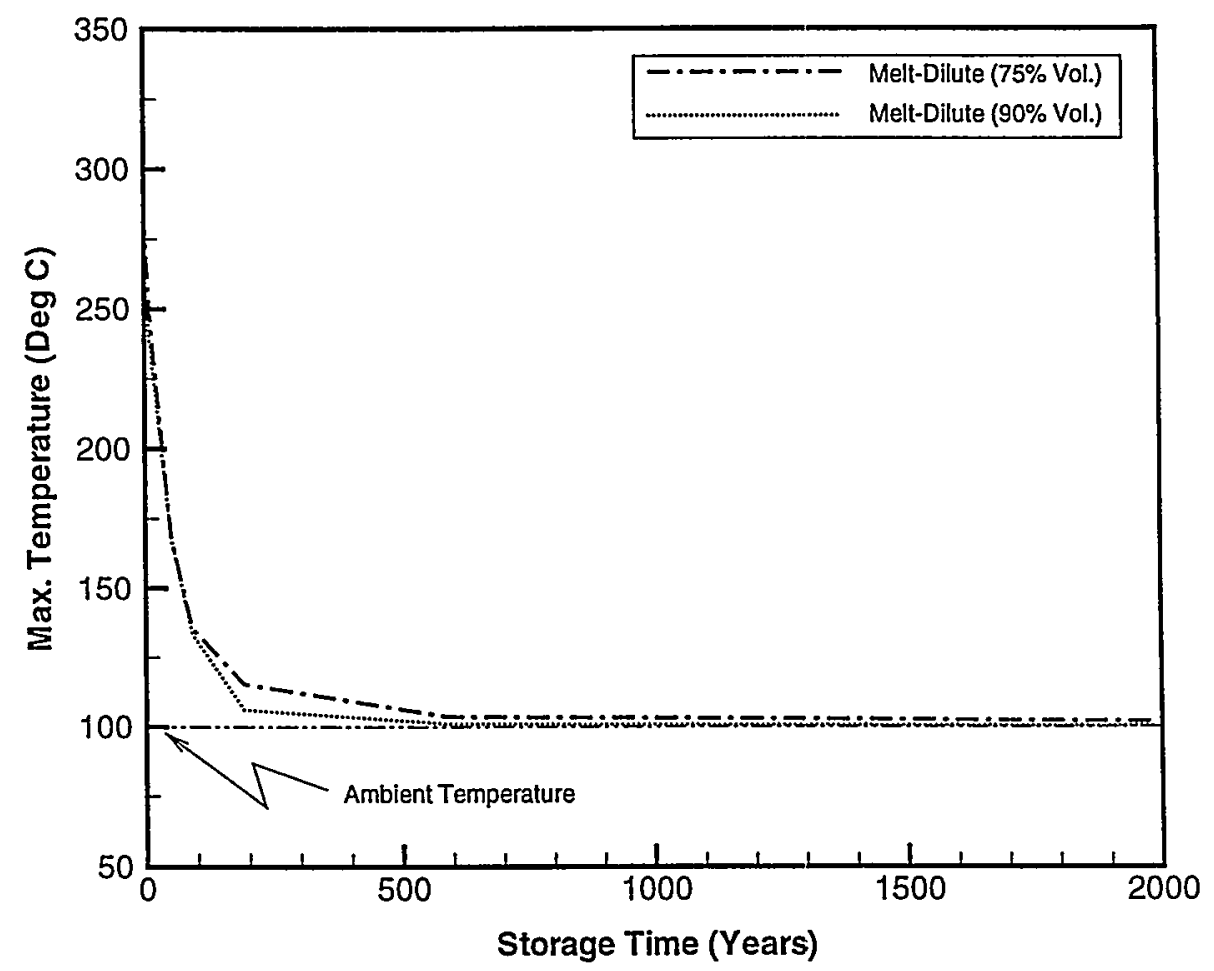

Figure 26. Comparison of maximum temperatures for $\mathrm{He}$-cooled $75 \%$ and $90 \%$ volume melt-dilute codisposal WP's for various storage times based on the baseline model. 


\section{Conclusions}

Three thermal models were developed to assess the thermal performance of the codisposal WP design using intact prototypic geometry created under the body-fitted coordinate system in the CFD preprocessing environment. They are the conduction model, the baseline model considering conduction-radiation coupled heat transfer mechanisms, and the detailed model including all three possible modes such as conduction, convection, and radiation energy transport processes.

The present analysis used well-defined decay heat loads for the SNF canister and HWGL. Reference model boundary conditions were provided by the WP performance requirements of a drift tunnel repository. In this report, two design options, direct spent fuel disposal and melt-dilute disposition options, were considered for the alternative SNF treatment. program using the codisposal WP configuration. The two-dimensional thermal performance analyses for various design options of the present codisposal WP configuration were performed mainly using the baseline model because of the computational efficiency.

However, the detailed model was used to investigate the physical heat transfer mechanism inside the codisposal waste package in detail under the reference design conditions defined in Table 1. In addition, the resuls of the detailed model provided quantitative estimation of the conservatism imbedded in the baseline model. The detailed model gave highly non-uniform package wall surface temperature such that top surface temperature of the WP is about $10^{\circ} \mathrm{C}$ higher than that of the bottom surface. On the other hand, as shown in Fig. 12, the baseline model results showed that top temperature is slightly lower than the bottom surface of the WP due to the neglect of internal buoyancy-driven gas circulation although the baseline model predicts the peak temperature similar to that of the detailed model. The detailed model results also showed that temperature gradients across the HWGL regions are much smaller compared to the predictions of the baseline model for a given elevation height from the bottom of the WP in a horizontal storage position. This is one of the evidences of the buoyancy-driven circulation internal to the codisposal WP. This phenomenon may be important in relation to the movement of water moisture around the WP surface inside a drift tunnel since the moisture directly affects corrosion of the WP materials. Peak temperatures with the detailed model are about $1^{\circ} \mathrm{C}$ lower than that of the baseline model. From the results of the conduction model, the radiative cooling mechanism is shown to be the most dominant cooling mode among the three possible cooling modes for higher than $130^{\circ} \mathrm{C}$ of the peak package temperature although detailed cooling mechanisms are quite different each other.

The results of the baseline model showed that both of the direct disposal and the meltdilute disposition options for the helium-filled WP satisfied the present waste acceptance criteria for the WP design under the reference boundary conditions in terms of the peak temperature criterion, $\mathrm{T}_{\max } \leq 350{ }^{\circ} \mathrm{C}$. A number of the melt-dilute form options are currently being assessed. Additional cases will be analyzed to update the results in this report. It should be emphasized that the results was based on the natural convective cooling mechanism without any help of external or forced circulation devices. In addition, 10 years' cooling time for the decay heat loads of the SNF and HWGL regions was used for the present analysis as one of the reference design conditions, but in reality the time for the WP to leave waste custodian and then to be transported to a repository site may be much longer than 10 years. 


\section{Recommendations}

The present work used a sensitivity analysis approach with respect to the reference design conditions. The baseline model/analysis tool should be used to assess the thermal performance of evolving and confirmed WP designs using better-defined geological boundary conditions to demonstrate compliance to the repository waste acceptance criteria.

The following recommendations are made for baseline model improvement:

- The present analysis used intact codisposal waste package with no internal structures to support SNF and waste glass logs since final geometrical configuration is neither confirmed nor available yet. The future model needs to include internal structure of the codisposal package to find out any impacts on the assessment of the WP thermal performance for the long-term storage.

- This report deals with the thermal performance internal to the codisposal WP. The thermal analysis modeling of hydro-geological media surrounding the WP, including the geological drift tunnel region, needs to be included to accurately model the repository temperature history. This would include the effects of water outside the WP. 


\section{References}

1. D. C. Losey, "Decay Heat Characterization of SRS Research Reactor Fuels", WSMS-CRT-97-0016 (February, 1998).

2. S. Y. Lee, "Three-Dimensional Thermal Analysis and Simulation of Dry Spent Nuclear Fuel Storage Canister Using CFDS-FLOW3D (U)", WSRC-TR-96-0059 (March, 1996).

3. "Mined Geologic Disposal System Draft Disposability Interface Specification," B00000000-0171704600-00108 REV 00, February 1998, prepared for U. S. Department of Energy, Yucca Mountain Site Characterization Office, by TRW Environmental Safety Systems, Inc.

4. R. L. Sindelar, "Plan for Direct/Co-Disposal Technology Development and Form Assessment for DOE Aluminum-Based Spent Nuclear Fuel", SRT-MTS-97-2030, October 7, 1997.

5. D. Vinson, "Preliminary Material Property Data", e-mail meaasage (September 5, 1997).

6. T. Adams, "Melt-Dilute Values", e-mail message, (February 6, 1998). Also see WSRC-RP-89-489 report.

7. A. J. Chapman, Heat Transfer, Third Edition, Macmillan Publishing Co., Inc,, (1974).

8. J. Jerrell, S. Y. Lee, and A. Shadday, "Thermal Analysis of the Failed Equipment Storage Vault System (U)", WSRC-TR-95-0288, (1995).

9. Kays, W. M. and Crawford, M. E., Convective Heat and Mass Transfer, Second Edition, McGraw-Hill Book Company, (1980).

10. S. V. Patankar, Numerical Heat Transfer and Fluid Flow, Hemisphere Publishing Corporation, (1980).

11. R. L. Sindelar, "Alternative Aluminum Spent Nuclear Fuel Treatment Technology Development Status Report (U)", WSRC-TR-97-00345 (October, 1997). 
WESTINGHOUSE SAVANNAH RIVER CO. REPORT WSRC-TR-98-00158

DISTRIBUTION

\section{SAVANNAH RIVER SITE}

W. Poulson, 704-C

S. Wood, 773-A

G. T. Wright, 773-A

G. H. Clare, 704-C

M. W. Barlow, 704-C

E. R. Conatser, 704-C

M. E. Dupont, 707-C

R. J. Skwarek, 704-C

W. F. Swift, 707-C

W. S. Large, 707-C

S. D. Burke, 707-C

J. N. Dewes, 707-C

W. S. Large, 707-C

G. Reynolds, 704-C

T. J. Worrell, 705-K

J. D. Cohen, 773-A

M. A. Ebra, 773-42A

C. P. Holding-Smith, 773-42A

C. R. Wolfe, 773-A

T. L. Capeletti, 773-41A

N. C. lyer, 773-A

M. R. Louthan, Jr., 773-A

S. Y. Lee, 773-42A

J. F. Krupa, 773-41A

H. B. Peacock, Jr., 773-A

T. M. Adams, 773-41A
P. S. Lam, 773-41A

W. F Ayres, 773-41A

D. W. Vinson, 773-41A

R. L. Sindelar, 773-41A

Site Records, 773-52A 